Subscriber access provided by Caltech Library

\title{
Article
}

\section{Tetranuclear [MnIIIMn3IVO4] Complexes as Spectroscopic Models of the S2 State of the Oxygen Evolving Complex in Photosystem II}

Heui Beom Lee, Angela A. Shiau, Paul H. Oyala, David A. Marchiori, Sheraz

Gul, Ruchira Chatterjee, Junko Yano, R. David Britt, and Theodor Agapie

J. Am. Chem. Soc., Just Accepted Manuscript • DOI: 10.1021/jacs.8b09961 • Publication Date (Web): 08 Nov 2018

Downloaded from http://pubs.acs.org on November 13, 2018

\section{Just Accepted}

"Just Accepted" manuscripts have been peer-reviewed and accepted for publication. They are posted online prior to technical editing, formatting for publication and author proofing. The American Chemical Society provides "Just Accepted" as a service to the research community to expedite the dissemination of scientific material as soon as possible after acceptance. "Just Accepted" manuscripts appear in full in PDF format accompanied by an HTML abstract. "Just Accepted" manuscripts have been fully peer reviewed, but should not be considered the official version of record. They are citable by the Digital Object Identifier (DOI@). "Just Accepted" is an optional service offered to authors. Therefore, the "Just Accepted" Web site may not include all articles that will be published in the journal. After a manuscript is technically edited and formatted, it will be removed from the "Just Accepted" Web site and published as an ASAP article. Note that technical editing may introduce minor changes to the manuscript text and/or graphics which could affect content, and all legal disclaimers and ethical guidelines that apply to the journal pertain. ACS cannot be held responsible for errors or consequences arising from the use of information contained in these "Just Accepted" manuscripts. 


\title{
Tetranuclear [Mn"IIMn $\left.{ }^{\mathrm{IV}} \mathrm{O}_{4}\right]$ Complexes as Spectroscopic Mod- els of the $\mathrm{S}_{2}$ State of the Oxygen Evolving Complex in Photo- system II
}

\author{
Heui Beom Lee ${ }^{\dagger}$, Angela A. Shiau ${ }^{\dagger}$, Paul H. Oyala ${ }^{\dagger}$, David A. Marchiori ${ }^{\ddagger}$, Sheraz Gul ${ }^{\S}$, Ruchira Chatterjee ${ }^{\S}$, Junko \\ Yano $^{\S}$, R. David Britt ${ }^{* \neq}$, and Theodor Agapie ${ }^{*+}$ \\ + Department of Chemistry and Chemical Engineering, California Institute of Technology, 1200 E California Blvd MC 127-72, Pasa- \\ dena, CA 91125, USA \\ ₹ Department of Chemistry, University of California, Davis, One Shields Ave, Davis, California 95616, USA \\ $\$$ Molecular Biophysics and Integrated Bioimaging Division, Lawrence Berkeley National Laboratory, Berkeley, CA 94720, USA
}

\begin{abstract}
Despite extensive biochemical, spectroscopic, and computational studies, the mechanism of biological water oxidation by the Oxygen Evolving Complex (OEC) of Photosystem II remains a subject of significant debate. Mechanistic proposals are guided by the characterization of reaction intermediates such as the $S_{2}$ state, which features two characteristic EPR signals at $g=2$ and $g=4.1$. Two nearly isoenergetic structural isomers have been proposed as the source of these distinct signals, but relevant structure-electronic structure studies remain rare. Herein, we report the synthesis, crystal structure, electrochemistry, XAS, magnetic susceptibility, variable temperature CW-EPR, and pulse EPR data for a series of $\left[\mathrm{Mn}^{\mathrm{III}} \mathrm{Mn}_{3}{ }^{\mathrm{IV}} \mathrm{O}_{4}\right]$ cuboidal complexes as spectroscopic models of the $\mathrm{S}_{2}$ state of the OEC. Resembling the oxidation state and EPR spectra of the

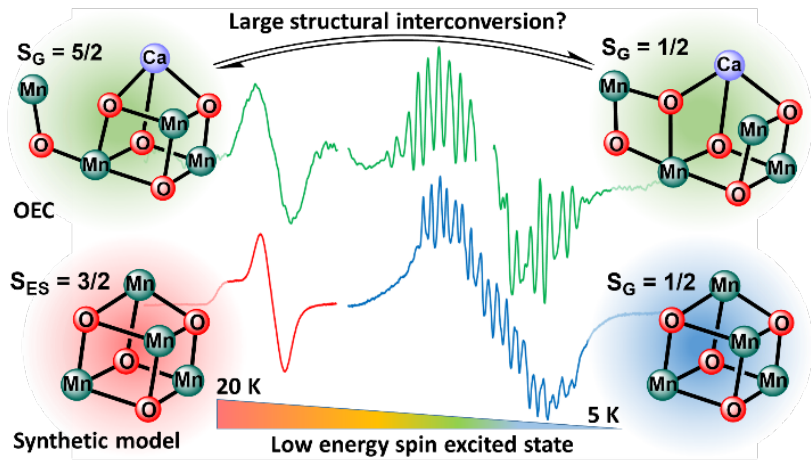
$\mathrm{S}_{2}$ state of the OEC, these model complexes show two EPR signals, a broad low field signal and a multiline signal, that are remarkably similar to the biological system. The effect of systematic changes in the nature of the bridging ligands on spectroscopy were studied. Results show that the electronic structure of tetranuclear $\mathrm{Mn}$ complexes is highly sensitive to even small geometric changes and the nature of the bridging ligands. Our model studies suggest that the spectroscopic properties of the OEC may also react very sensitively to small changes in structure; the effect of protonation state and other reorganization processes need to be carefully assessed.
\end{abstract}

\section{INTRODUCTION}

Structural determination and spectroscopic characterization of intermediates (and derivatives thereof) in the S-state catalytic cycle of the Oxygen Evolving Complex (OEC) of Photosystem II (PSII) heavily influence mechanistic proposals for $\mathrm{O}-\mathrm{O}$ bond formation. ${ }^{1-}$ ${ }^{14}$ The dark-stable $\mathrm{S}_{1}$ state of the OEC consists of a CaMn${ }_{4} \mathrm{O}_{5}$ cluster with $\mathrm{Mn}$ oxidation states $\mathrm{Mn}^{\mathrm{III}}{ }_{2} \mathrm{Mn}^{\mathrm{IV}}{ }_{2 \cdot}{ }^{15}$ Light-induced one electron oxidation of the $S_{1}$ state results in the formation of the $S_{2}$ state, with two characteristic EPR transitions centered at $g=2$ and $g=4.1$. ${ }^{9,11}$, ${ }^{13,16}$ Two additional one electron oxidations lead to the formation of $\mathrm{S}_{3}$ and $\mathrm{S}_{4}$ states, respectively, and dioxygen is evolved following formation of the elusive $\mathrm{S}_{4}$ state. ${ }^{17}$ Chemical changes such as $\mathrm{Ca}^{2+}$ removal or treatment with $\mathrm{NH}_{3}$ or $\mathrm{F}^{-}$inhibit the $\mathrm{S}_{2} \rightarrow \mathrm{S}_{3}$ transition specifically, highlighting opportunities for mechanistic insight, ${ }^{4}, 18$ but also the need for benchmarking with well characterized synthetic models. Constrained by available data from XAS and EPR spectroscopy, the current understanding of the $S_{2}$ state structure is based on theoretical studies starting from the high-resolution $(1.95 \AA)$, radiation damage-free $X$-ray structure of the $S_{1}$ state. ${ }^{19-20}$ Each EPR signal in the $S_{2}$ state is proposed to originate from different structures (Fig. 1): an "open cubane" structure with a low-spin (LS) $S=1 / 2$ ground state and a "closed cubane" structure with a high-spin (HS) $S=5 / 2$ ground state. ${ }^{21-23}$ The interconvertibility of the two EPR signals suggest a small energy difference between these two structures; IR irradiation of the LS form at 120-150 K results in the formation of the HS form, which can be reverted to the LS form by annealing at 200 $\mathrm{K} .{ }^{11}$ The two structural isomers effectively differ only by the relative position of the bridging $\mathrm{O}(5)$ oxygen, a water derived oxygen, which is proposed to undergo $\mathrm{O}-\mathrm{O}$ coupling to generate $\mathrm{O}_{2}{ }^{24-25}$ Time-resolved, femtosecond X-ray free electron laser (XFEL) techniques offer the possibility of observing structural and spectroscopic changes in the OEC under dynamic, catalytically active conditions. ${ }^{26-31}$ For such studies, further improvements in resolution and issues with $S$ state heterogeneity and deconvolution remain to be addressed. ${ }^{27,31-}$ 32

Growing experimental data support that conversion from the LS form of the $S_{2}$ state to its HS form is an intermediate step in the 

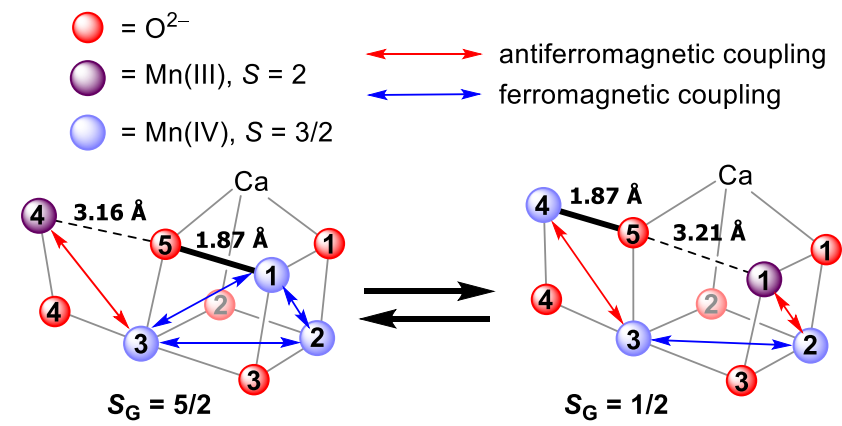

Figure 1. Computed structures for the proposed isomers of the inorganic $\mathrm{CaMn}_{4} \mathrm{O}_{5}$ core of the OEC in the $\mathrm{S}_{2}$ state. The large structural changes in the Mn-oxo distances have been calculated to lead to different electronic coupling between the Mn centers and a change in the spin ground state $\left(S_{\mathrm{G}}\right)$, which explain the two observed EPR signals. $\mathrm{Mn}(4)-\mathrm{O}(5)$ and $\mathrm{Mn}(1)-\mathrm{O}(5)$ distances shown with bold and dashed lines. Nature of the computed magnetic exchange coupling interactions shown in red (antiferromagnetic) and blue (ferromagnetic) arrows. Adapted from ref. 22.

$\mathrm{S}_{2} \rightarrow \mathrm{S}_{3}$ transition. ${ }^{33} \mathrm{pH}$ dependence studies indicate that deprotonation of the LS form leads to the HS form. ${ }^{34}$ Structural changes following deprotonation are unknown, but computational studies suggest that the electronic structure of the OEC is highly sensitive to small changes in structure as reported by EPR spectroscopy. ${ }^{35}$ Deprotonation of a Mn-bound water and/or a reorientation of a Glu residue in the $S_{2}$ state may perturb the ground spin state from LS to HS, indicating that spectroscopic properties may react very sensitively to small geometric changes that do not lead to significant changes in the total energy of the cluster. ${ }^{35}$ EXAFS studies support structural differences between the species responsible for the $g=2$ and the $g=4.1$ signal, but further atomistic details are unknown. ${ }^{36-37}$

In contrast to the extensive studies performed on the $S_{2}$ state of the OEC, structural and spectroscopic studies of $\mathrm{Mn}^{\mathrm{III}} \mathrm{Mn}_{3}{ }^{\mathrm{IV}}$ model complexes remain rare ${ }^{38-40}$, and can be summarized as follows. The phosphinate-bridged, cuboidal complex $\left[\mathrm{Mn}_{4} \mathrm{O}_{4}\left(\mathrm{Ph}_{2} \mathrm{PO}_{2}\right)_{6}\right]^{+}$shows a broad EPR spectrum. ${ }^{41}$ The $g=4.1$ signal of the adamantaneshaped complex $\left[\mathrm{Mn}_{4} \mathrm{O}_{6}(\text { bpea })_{4}\right]^{3+}$ has been assigned to the first excited Kramers doublet of an $S=5 / 2$ ground state determined from magnetization data. ${ }^{42}$ Starting from a linear-chain precursor, a putative complex $\left[\mathrm{Mn}_{4} \mathrm{O}_{6}(\text { bpy })_{6}\right]^{3+}$ was generated by radiolysis and features a multiline signal centered at $g=2$ consistent with an $S=1 / 2$ ground state. ${ }^{43}$ In-situ oxidation of a close OEC structural model complex, $\mathrm{CaMn}_{4} \mathrm{O}_{4}(\mathrm{OPiv})_{8}$, gives rise to two EPR signals at $g=4.9$ and $g=2$, attributed to different spin states of the cluster corresponding to a $\left[\mathrm{CaMn}_{4} \mathrm{O}_{4}(\mathrm{OPiv})_{8}\right]^{+}$species, although further structural, spectroscopic, and magnetic data have not been provided. ${ }^{44}$ Follow-up computational studies disagree on the assignment of the two signals, one of them suggesting that the two signals must be due to structurally very different clusters. ${ }^{45-46}$ In general, systematic studies that probe the effect of small structural changes on the spectroscopic and magnetic properties of $S_{2}$ model clusters are very rare, likely due to the synthetic challenges of accessing a series of isolable clusters that are suitable for comparisons. ${ }^{47-48}$ Indeed, despite significant efforts to prepare tetra- and penta-nuclear clusters that are relevant to the S-state intermediates in terms of structure, redox state, or spectroscopy, accurate models for benchmarking against the biological system are rare. ${ }^{41,47,49-69}$

Herein, we report the synthesis, crystal structure, electrochemistry, XAS, SQUID magnetometry, variable temperature CW-EPR, and pulse EPR data for a series of $\left[\mathrm{Mn}^{\mathrm{III}} \mathrm{Mn}_{3}{ }^{\mathrm{IV}} \mathrm{O}_{4}\right]$ cuboidal complexes. Results show that the electronic structures of tetranuclear
Mn complexes are highly sensitive to even small geometric changes promoted by the nature of the supporting ligands. Similar to the computational studies performed on the $S_{2}$ state, our experimental studies on model clusters suggest that the spectroscopic properties of the OEC may also react very sensitively to small changes in structure.

\section{RESULTS}

Synthesis, crystal structure, and electrochemistry of $\left[\mathrm{Mn}^{\mathrm{III}} \mathrm{Mn}_{3}{ }^{\mathrm{IV}} \mathrm{O}_{4}\right]$ complexes. One electron reduced $\left[\mathrm{Mn}_{2}{ }^{\mathrm{II}} \mathrm{Mn}_{2}{ }^{\mathrm{IV}} \mathrm{O}_{4}\right]$ cuboidal complexes were chosen as precursors for the targeted $\left[\mathrm{Mn}^{\mathrm{III}} \mathrm{Mn}_{3}{ }^{\mathrm{IV}} \mathrm{O}_{4}\right]$ complexes. We have previously reported the synthesis of $\mathrm{LMn}_{2}{ }^{\mathrm{II}} \mathrm{Mn}_{2}{ }^{\mathrm{IV}} \mathrm{O}_{4}(\mathrm{OAc})_{3}\left(\mathbf{1}\right.$, Scheme 1) ${ }^{56-57,70}$ The cyclic voltammogram $(\mathrm{CV})$ of 1 shows a reversible redox process at $+250 \mathrm{mV}$ vs. $\mathrm{Fc} / \mathrm{Fc}^{+}$assigned to the $\left(\mathrm{Mn}_{2}{ }^{\mathrm{II}} \mathrm{Mn}_{2}{ }^{\mathrm{IV}}\right) /\left(\mathrm{Mn}^{\mathrm{III}} \mathrm{Mn}_{3}{ }^{\mathrm{IV}}\right)$ couple. Treatment of 1 with 1 equiv. of $\left[(4-\mathrm{BrPh})_{3} \mathrm{~N}\right]\left[\mathrm{SbCl}_{6}\right]$ results in the formation of an unstable species, but rapid freeze-quenching of the reaction mixture allowed the observation of an intense EPR spectrum with a broad signal centered at $g=2$ featuring Mn hyperfine interactions, consistent with an $S=1 / 2$ ground state (Fig S17). In contrast, the phosphinate-bridged cuboidal complex $\left[\mathrm{Mn}_{4} \mathrm{O}_{4}\left(\mathrm{Ph}_{2} \mathrm{PO}_{2}\right)_{6}\right]^{+}$has a higher spin ground state $\mathrm{S} \geq 3 / 2$. The product of oxidation of 1 features other broad EPR signals at $g>2$ that can be assigned to spin excited states or decomposition products, but further investigation was not pursued.

Based on the reduction potential of the isolable $\left[\mathrm{Mn}_{4} \mathrm{O}_{4}\left(\mathrm{Ph}_{2} \mathrm{PO}_{2}\right)_{6}\right]^{+}$complex at $+680 \mathrm{mV}$ vs. $\mathrm{Fc} / \mathrm{Fc}^{+}$, we targeted oxidatively stable phosphinate-bridged complexes. ${ }^{41,61}$ Treatment of 1 with 3 equiv. $\mathrm{HO}_{2} \mathrm{PPh}_{2}$ in THF leads to the formation of 2 via a protonolysis reaction (Scheme 1). The ESI-MS peak at $\mathrm{m} / \mathrm{z}=1792$ is consistent with the mass of $\left[\mathrm{LMn}_{4} \mathrm{O}_{4}\left(\mathrm{O}_{2} \mathrm{PPh}_{2}\right)_{3}\right]^{+}$. The X-ray crystal structure of $\mathbf{2}$ is consistent with the $\mathrm{LMn}_{4} \mathrm{O}_{4}\left(\mathrm{O}_{2} \mathrm{PPh}_{2}\right)_{3}$ formulation (Fig. 2). Based on Mn-oxo distances, the oxidation states of $\mathrm{Mn}(1)$ and $\mathrm{Mn}(2)$ are assigned to $\mathrm{Mn}^{\mathrm{IV}}$, and those of $\mathrm{Mn}(3)$ and $\mathrm{Mn}(4)$ to $\mathrm{Mn}^{\mathrm{III}}$. Axial elongation of $\mathrm{Mn}^{\mathrm{III}}$-oxo distances is observed, at 2.177(2) and 2.187(2) $\AA$ for $\mathrm{Mn}(3)$ and $\mathrm{Mn}(4)$, respectively. These are due to population of a $\mathrm{dz}^{2}-\sigma$ antibonding orbital. Given the heteroleptic coordination around $\mathrm{Mn}(3)$, the Jahn-Teller effect is not invoked to describe the observed distortion. The coordination environment around $\mathrm{Mn}(4)$ can be viewed as pseudo- $C_{3 \mathrm{v}}$, in which case a Jahn-Teller elongation can be invoked to remove the degeneracy of the ${ }^{5} E$ ground state. ${ }^{71-72}$ Similar $\mathrm{Mn}^{\mathrm{III}}-$ oxo elongations were observed for 1, at 2.201(2) and 2.234(2) $\AA$. The CV of $\mathbf{2}$ shows a reversible redox process at $+190 \mathrm{mV}$ vs. $\mathrm{Fc} / \mathrm{Fc}^{+}$assigned to the $\left(\mathrm{Mn}_{2}{ }^{\mathrm{III}} \mathrm{Mn}_{2}{ }^{\mathrm{IV}}\right) /\left(\mathrm{Mn}^{\mathrm{III}} \mathrm{Mn}_{3}{ }^{\mathrm{IV}}\right)$ couple (Fig. 3). Treatment of 2 with 1 equiv. of $\left[(4-\mathrm{BrPh})_{3} \mathrm{~N}\right][\mathrm{OTf}]$ leads to the formation of the one-electron oxidized species 2-ox. ${ }^{73}$ The ESI-MS and crystal structure of 2ox is consistent with the $\mathrm{LMn}_{4} \mathrm{O}_{4}\left(\mathrm{O}_{2} \mathrm{PPh}_{2}\right)_{3}(\mathrm{OTf})$ formulation (Fig. 2). Based on $\mathrm{Mn}-$ oxo distances, the oxidation state of $\mathrm{Mn}(4)$ is assigned as $\mathrm{Mn}^{\mathrm{III}}$. The elongated $\mathrm{Mn}(4)-\mathrm{O}(4)$ distance of $2.241(1) \AA$ is consistent with this assignment.

Toward expanding the series of $\mathrm{Mn}_{4}$ clusters with the same redox state as the $\mathrm{S}_{2}$ state of the OEC, other supporting ligands were targeted. Based on the precedent that amidate ligands have been employed for the synthesis of a high oxidation state $\mathrm{Mn}^{\mathrm{V}}$-oxo complex, ${ }^{74}$ we targeted a related class of oxidatively stable amidate-bridged $\left[\mathrm{Mn}_{4} \mathrm{O}_{4}\right]$ cuboidal complexes. In contrast to the vast number of carboxylate-bridged high oxidation state metal-oxo clusters, amidatebridged metal-oxo clusters are rare. ${ }^{75-78} \mathrm{We}$ employed an $n$-propyllinked diacetamide proligand $\left(\mathrm{H}_{2}\right.$ diam $)$ to replace two acetate moieties. Treatment of 1 with 1 equiv. $\mathrm{H}_{2}$ diam and 2 equiv. $\mathrm{NaO}^{\prime} \mathrm{Bu}$ in 
Scheme 1. Synthesis of complexes 2 4 and their one-electron oxidized analogues 2-ox $\sim$ 4-ox.

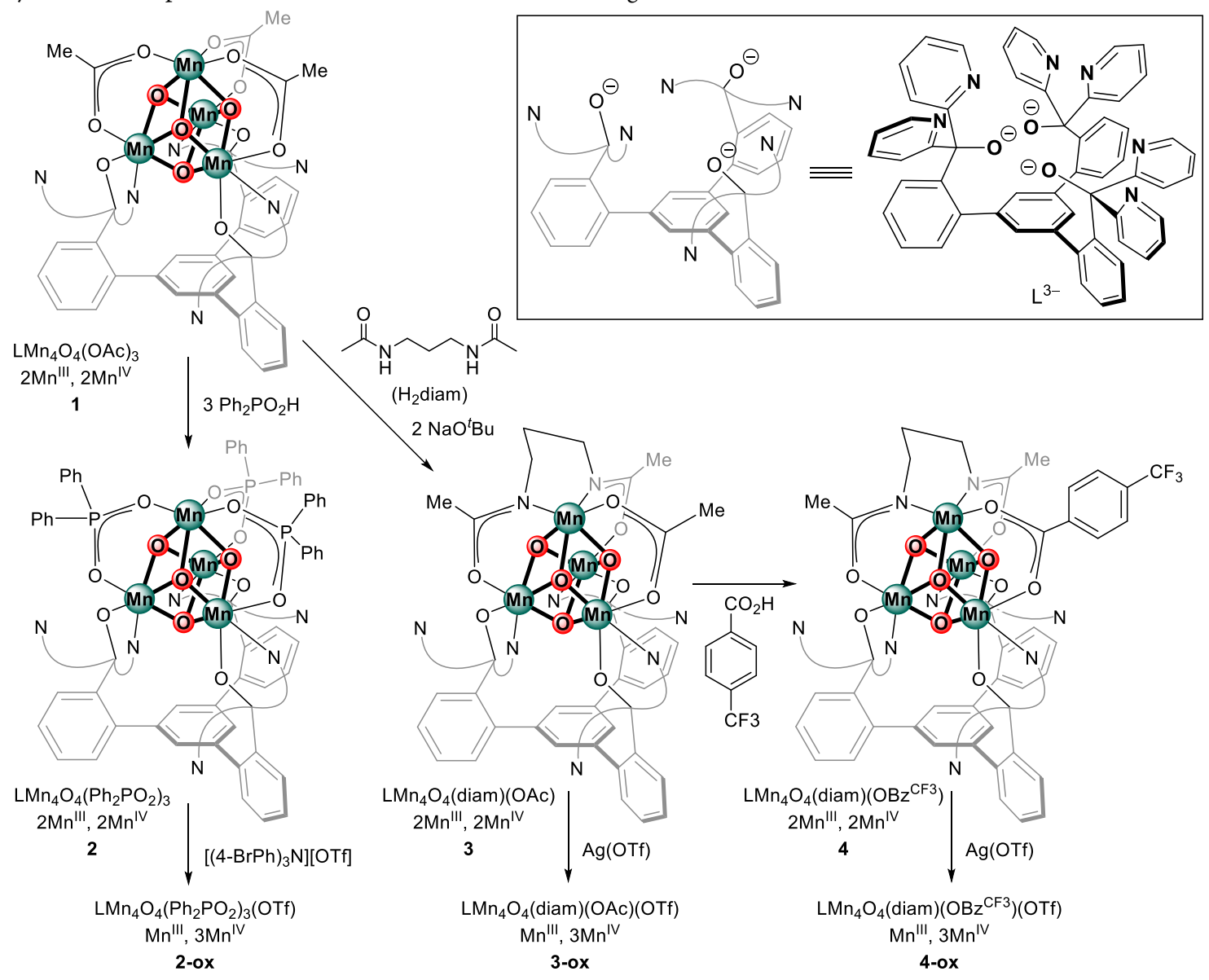

DMF leads to the formation of 3 (Scheme 1). The ESI-MS and crystal structure of 3 are consistent with the $\mathrm{LMn}_{4} \mathrm{O}_{4}($ diam $)(\mathrm{OAc})$ formulation. A smaller variation of $\mathrm{Mn}$-oxo distances is observed in 3, ranging from $1.860(2)$ to $2.087(2) \AA$. The $n$-propyl-linked diamidate serves as a bridging ligand across two faces of the $\left[\mathrm{Mn}_{4} \mathrm{O}_{4}\right]$ cubane moiety, resulting in a pseudo- $C_{S}$ symmetric complex. The reversible $\left(\mathrm{Mn}_{2}{ }^{\mathrm{II}} \mathrm{Mn}_{2}{ }^{\mathrm{IV}}\right) /\left(\mathrm{Mn}^{\mathrm{III}} \mathrm{Mn}_{3}{ }^{\text {IV }}\right)$ couple is observed at $-150 \mathrm{mV}$ vs. Fc/ $\mathrm{Fc}^{+}$(Fig. 3). The diamidate ligand decreases the oxidation potential by $400 \mathrm{mV}$ relative to that of 1 . Treatment of 3 with 1 equiv. $\mathrm{Ag}$ (OTf) leads to the formation of the one-electron oxidized species 3-ox. The ESI-MS and crystal structure of 3-ox are consistent with the $\mathrm{LMn}_{4} \mathrm{O}_{4}$ (diam)(OAc)(OTf) formulation (Fig. 2). The oxidation state of $\mathrm{Mn}(3)$ is assigned as $\mathrm{Mn}^{\mathrm{III}}$ in 3-ox. With the exception of an elongated $\mathrm{Mn}(3)-\mathrm{O}(3)$ distance of 2.051(4) $\AA$, all other $\mathrm{Mn}$-oxo distances are in the range 1.893(4)-1.937(4) $\AA$, consistent with the $\mathrm{Mn}^{\text {III }} \mathrm{Mn}_{3}{ }^{\text {IV }}$ oxidation state assignment.

To further investigate the effect of small geometric changes on the electronic structure of the resulting cluster, a diamidate-benzoate complex was targeted. ${ }^{79}$ Treatment of 3 with 1 equiv. of $\mathrm{p}$ $\mathrm{CF}_{3} \mathrm{C}_{6} \mathrm{H}_{4} \mathrm{CO}_{2} \mathrm{H}\left({ }^{\mathrm{CF} 3} \mathrm{BzOH}\right)$ leads to the formation of 4 via a protonolysis reaction (Scheme 1 ). The ESI-MS peak at $\mathrm{m} / \mathrm{z}=1485$ is consistent with the mass of $\left[\mathrm{LMn}_{4} \mathrm{O}_{4}(\mathrm{diam})\left(\mathrm{OBz}^{\mathrm{CF} 3}\right)\right]^{+}$. The $\mathrm{CV}$ of 4 shows a reversible redox process at $-15 \mathrm{mV}$ vs. $\mathrm{Fc} / \mathrm{Fc}^{+}$assigned to the $\left(\mathrm{Mn}_{2}{ }^{\mathrm{III}} \mathrm{Mn}_{2}{ }^{\mathrm{IV}}\right) /\left(\mathrm{Mn}^{\mathrm{III}} \mathrm{Mn}_{3}{ }^{\mathrm{IV}}\right)$ couple (Fig. 3$)$. The positive shift by $135 \mathrm{mV}$ relative to that of 3 is consistent with the decreased basicity of $\mathrm{OBz}^{-}$compared to $\mathrm{OAc}^{-80-81}$ Treatment of 4 with 1 equiv. $\mathrm{Ag}(\mathrm{OTf})$ leads to the formation of the one-electron oxidized species 4-ox. The $\mathrm{LMn}_{4} \mathrm{O}_{4}($ diam $)(\mathrm{OBz})(\mathrm{OTf})$ formulation is consistent with the crystal structure (Fig. 2). Similar to 3-ox, the oxidation state of $\mathrm{Mn}(3)$ is assigned as $\mathrm{Mn}^{\text {III }}$. An elongated $\mathrm{Mn}(3)-\mathrm{O}(3)$ distance of 2.143(3) Å is consistent with the $\mathrm{Mn}^{\mathrm{III}} \mathrm{Mn}_{3}{ }^{\mathrm{IV}}$ assignment. Overall, comparing complexes 2-ox, 3-ox, and 4-ox, the elongated $\mathrm{Mn}^{\mathrm{III}}$-oxo distance varies from 2.241(1), to 2.051(4), and 2.143(3), while the other Mn-oxo distances are in the range 1.831(1)-1.976(2) $\AA$, $1.893(4)-1.937(4) \AA$, and 1.873(3)-1.965(3) A, respectively. For 2-ox, 3-ox, and 4-ox, the redox potential for the reversible $\left(\mathrm{Mn}_{2}{ }^{\mathrm{III}} \mathrm{Mn}_{2}{ }^{\mathrm{IV}}\right) /\left(\mathrm{Mn}^{\mathrm{III}} \mathrm{Mn}_{3}{ }^{\mathrm{IV}}\right)$ couple was measured at $+190 \mathrm{mV}$, $-150 \mathrm{mV}$, and $-15 \mathrm{mV}$ vs. $\mathrm{Fc} / \mathrm{Fc}^{+}$, respectively. In comparison, the estimated midpoint redox potential for the $\left(S_{1} / S_{2}\right)$ couple in the OEC was estimated at $+900 \mathrm{mV}$ vs. SHE, which is approximately $+250 \mathrm{mV}$ vs. $\mathrm{Fc} / \mathrm{Fc}^{+}{ }^{82}$

XAS spectroscopy. Solution and solid-state Mn K-edge X-ray absorption near-edge spectroscopy (XANES) and extended X-ray absorption fine structure (EXAFS) were used to further characterize the metal oxidation states and to provide evidence of structural integrity in solution (Fig. S12-S13). Absorption edge positions were determined from the second-derivative zero-crossings, giving the following values (eV): 6553.3 (2-ox), 6552.8 (3-ox), 6553.3 (4-ox). These values are comparable to $6553.1\left(\mathrm{~S}_{1}\right)$ and $6554.1\left(\mathrm{~S}_{2}\right)$ from cyanobacteria PSII. ${ }^{20}$ Solution EXAFS data for 2-ox, 3-ox, and 4-ox are indistinguishable from the corresponding solid-state EXAFS data and are consistent with the solid state structural assignments (Fig. 4).

Magnetometry. To obtain insight into the magnetic exchange coupling interactions between the Mn centers, magnetic susceptibility measurements were performed on powdered crystalline samples of 2-ox, 3-ox, and 4-ox in the temperature range $1.8 \mathrm{~K}-300 \mathrm{~K}$ at a non-saturating field of $0.4 \mathrm{~T}$. For 2-ox, the $\chi \mathrm{T}$ value of $5.64 \mathrm{emu} \mathrm{K}$ $\mathrm{mol}^{-1}$ at $300 \mathrm{~K}$ indicates antiferromagnetic coupling between the Mn centers, deviating from the expected spin-only value of $8.62 \mathrm{emu}$ $\mathrm{K} \mathrm{mol}^{-1}(g=2)$ for uncoupled $\mathrm{Mn}^{\mathrm{III}}(S=2)$ and $\mathrm{Mn}^{\mathrm{IV}}(S=3 / 2)$ cen- 

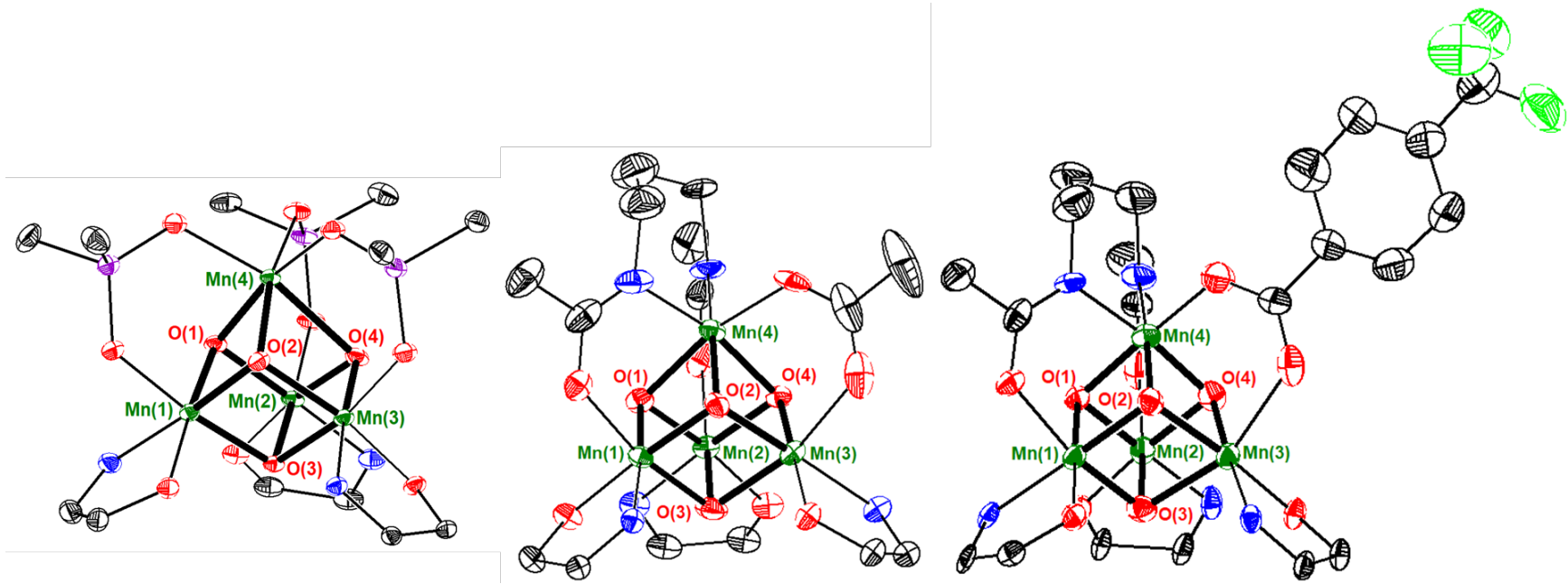

Figure 2. Truncated crystal structures of 2-ox (left), 3-ox (middle), and 4-ox (right). Mn (green), O (red), N (blue), P (purple), C (black), F (light green). Bolded bonds highlight metal-oxo bonds. Selected bond distances $(\AA)$ :

2-ox: $\mathrm{Mn}(1)-\mathrm{O}(1)$ 1.920(1), $\mathrm{Mn}(1)-\mathrm{O}(2)$ 1.862(1), $\mathrm{Mn}(1)-\mathrm{O}(3)$ 1.919(1), $\mathrm{Mn}(2)-\mathrm{O}(1)$ 1.898(1), $\mathrm{Mn}(2)-\mathrm{O}(3) 1.920(1), \mathrm{Mn}(2)-\mathrm{O}(4)$ $1.858(1), \mathrm{Mn}(3)-\mathrm{O}(2)$ 1.931(1), $\mathrm{Mn}(3)-\mathrm{O}(3)$ 1.929(1), $\mathrm{Mn}(3)-\mathrm{O}(4)$ 1.831(1), $\mathrm{Mn}(4)-\mathrm{O}(1) 1.932(1), \mathrm{Mn}(4)-\mathrm{O}(2) 1.976(2), \mathrm{Mn}(4)-\mathrm{O}(4)$ 2.241(1), $\mathrm{Mn}(1)-\mathrm{Mn}(2)$ 2.8862(8), $\mathrm{Mn}(1)-\mathrm{Mn}(3)$ 2.8803(7), $\mathrm{Mn}(2)-\mathrm{Mn}(3)$ 2.8477(5), $\mathrm{Mn}(1)-\mathrm{Mn}(4) 2.8512(6), \mathrm{Mn}(2)-\mathrm{Mn}(4) 2.9288(6)$, $\operatorname{Mn}(3)-\operatorname{Mn}(4) 2.9585(7)$.

3-ox: $\mathrm{Mn}(1)-\mathrm{O}(1)$ 1.909(5), $\mathrm{Mn}(1)-\mathrm{O}(2)$ 1.896(3), $\mathrm{Mn}(1)-\mathrm{O}(3)$ 1.937(4), $\mathrm{Mn}(2)-\mathrm{O}(1)$ 1.893(4), $\mathrm{Mn}(2)-\mathrm{O}(3)$ 1.931(5), $\mathrm{Mn}(2)-\mathrm{O}(4)$ 1.899(3), $\mathrm{Mn}(3)-\mathrm{O}(2)$ 1.911(4), $\mathrm{Mn}(3)-\mathrm{O}(3)$ 2.051(4), $\mathrm{Mn}(3)-\mathrm{O}(4)$ 1.926(4), $\mathrm{Mn}(4)-\mathrm{O}(1) 1.897(4), \mathrm{Mn}(4)-\mathrm{O}(2) 1.909(4), \mathrm{Mn}(4)-\mathrm{O}(4)$ 1.901(4), $\mathrm{Mn}(1)-\mathrm{Mn}(2)$ 2.899(2), $\mathrm{Mn}(1)-\mathrm{Mn}(3)$ 2.946(1), $\mathrm{Mn}(2)-\operatorname{Mn}(3)$ 2.962(1), $\operatorname{Mn}(1)-\operatorname{Mn}(4) 2.777(1), \operatorname{Mn}(2)-\operatorname{Mn}(4) 2.758(1)$, $\operatorname{Mn}(3)-\operatorname{Mn}(4) 2.804(1)$.

4-ox: $\mathrm{Mn}(1)-\mathrm{O}(1)$ 1.901(2), $\mathrm{Mn}(1)-\mathrm{O}(2)$ 1.873(3), $\mathrm{Mn}(1)-\mathrm{O}(3)$ 1.874(3), $\mathrm{Mn}(2)-\mathrm{O}(1)$ 1.880(3), $\mathrm{Mn}(2)-\mathrm{O}(3) 1.892(3), \mathrm{Mn}(2)-\mathrm{O}(4)$ 1.902(3), $\mathrm{Mn}(3)-\mathrm{O}(2)$ 1.926(3), $\mathrm{Mn}(3)-\mathrm{O}(3)$ 2.143(3), $\mathrm{Mn}(3)-\mathrm{O}(4)$ 1.965(3), $\mathrm{Mn}(4)-\mathrm{O}(1) 1.894(3), \mathrm{Mn}(4)-\mathrm{O}(2) 1.917(3), \mathrm{Mn}(4)-\mathrm{O}(4)$ 1.883(3), $\mathrm{Mn}(1)-\mathrm{Mn}(2)$ 2.8725(6), $\mathrm{Mn}(1)-\mathrm{Mn}(3)$ 2.9352(9), $\mathrm{Mn}(2)-\mathrm{Mn}(3)$ 2.989(1), Mn(1)-Mn(4) 2.7593(7), $\mathrm{Mn}(2)-\mathrm{Mn}(4) 2.7464(8)$, $\operatorname{Mn}(3)-\operatorname{Mn}(4) 2.840(1)$.

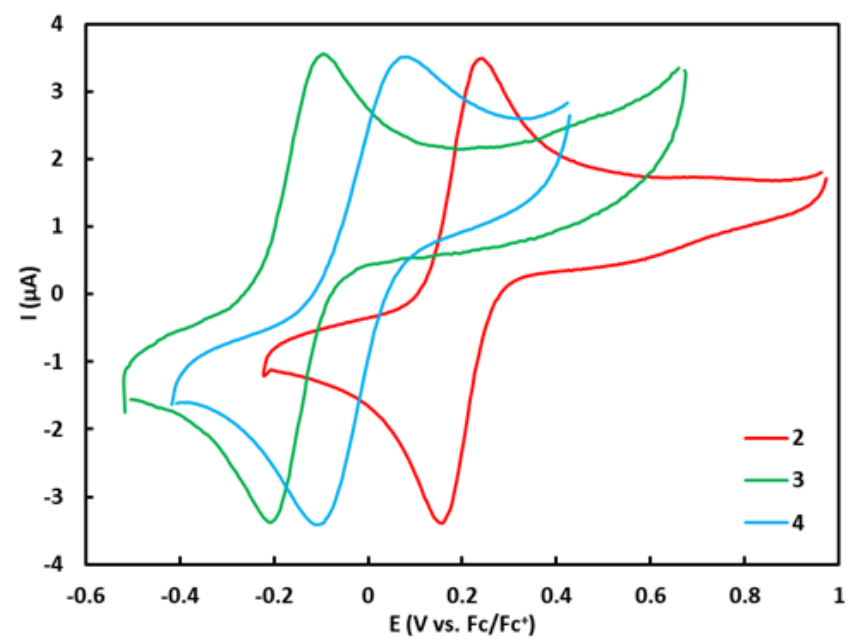

Figure 3. $\mathrm{CV}$ of complexes 2, 3, and 4. Measured $\mathrm{E}_{1 / 2}:-150 \mathrm{mV}$ (3), $-15 \mathrm{mV}(4),+190 \mathrm{mV}(2)$ vs. $\mathrm{Fc} / \mathrm{Fc}^{+}$. Estimated $\mathrm{E}_{1 / 2}\left(\mathrm{~S}_{1} / \mathrm{S}_{2}\right):+250 \mathrm{mV}$ vs. $\mathrm{Fc} / \mathrm{Fc}^{+}$(ref. 29).

ters (Fig. 5). $\chi \mathrm{T}$ decreases monotonically with temperature, reaching a value of $0.383 \mathrm{emu} \mathrm{K} \mathrm{mol}{ }^{-1}$ at $1.8 \mathrm{~K}$, in good agreement with the expected $\chi \mathrm{T}$ value of $0.375 \mathrm{emu} \mathrm{K} \mathrm{mol}{ }^{-1}$ for an $S=1 / 2(g=2)$ ground state. The near-ideal Curie behavior observed between $1.8-10 \mathrm{~K}$ can be attributed to the absence of thermally accessible spin excited states $S>1 / 2$ in this temperature range. Using software that employs an exact solution to the isotropic spin exchange Hamiltonian (Eq. 1) ${ }^{83}$, an exchange coupling model that consists of two edge-sharing isosceles triangles with vertices at $\mathrm{Mn}(1)-\mathrm{Mn}(2)$ $\mathrm{Mn}(3)$ and $\mathrm{Mn}(2)-\mathrm{Mn}(3)-\mathrm{Mn}(4)$ was employed to fit the susceptibility data. This model takes into account the pseudo- $\mathrm{C}_{\mathrm{s}}$ symmetry of the $\left[\mathrm{Mn}_{4} \mathrm{O}_{4}\right]$ core, with the mirror plane containing the $\mathrm{Mn}(4)$ -

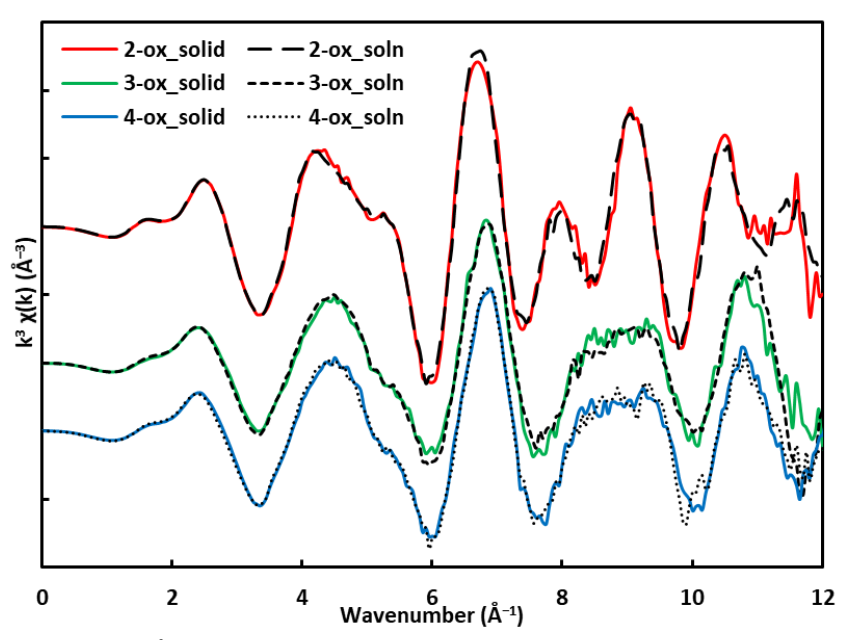

Figure 4. $\mathrm{k}^{3}$-weighted $\mathrm{k}$-space EXAFS data at Mn K-edge for complexes 2-ox, 3-ox, and 4-ox in solid and solution phases highlighting the integrity of the complexes in solution.

$\mathrm{Mn}(1)$ and $\mathrm{Mn}(4)-\mathrm{O}(4)$ vectors and bisecting the $\mathrm{Mn}(2)-\mathrm{Mn}(3)$ vector. The following parameters were used to fit the data: $J_{12}=J_{13}=$ $-8.8 \mathrm{~cm}^{-1}, J_{23}=-18.7 \mathrm{~cm}^{-1}, J_{14}=-21.0 \mathrm{~cm}^{-1}, J_{24}=J_{34}=-3.2 \mathrm{~cm}^{-1}, g$ $=2.00$. The smaller $J_{24}=J_{34}$ coupling is expected given the elongated $\mathrm{Mn}(4)-\mathrm{O}(4)$ distance of 2.241(1) A. Simulating the susceptibility data assuming single-site zero field splitting parameters $D\left(\mathrm{Mn}^{\mathrm{IV}}\right)=$ $0 \mathrm{~cm}^{-1}$ and $D\left(\mathrm{Mn}^{\mathrm{III}}\right)=0,-2$, or $-4 \mathrm{~cm}^{-1}$ did not result in significant differences in $J$. Values of $D \approx-0.2 \mathrm{~cm}^{-1}$ and $D \approx-4 \mathrm{~cm}^{-1}$ are typical for 6-coordinate $\mathrm{Mn}^{\mathrm{IV}}$ and $\mathrm{Mn}^{\mathrm{III}}$, respectively. ${ }^{17,84-85}$ The calculated energy level diagram indicates a quartet excited state c.a. $28 \mathrm{~cm}^{-1}$ (equivalent temperature of $40 \mathrm{~K}$ ) above the doublet ground state (Fig. S14). This energy separation is comparable to the $25-35 \mathrm{~cm}^{-1}$ measured for $\mathrm{MeOH}$-treated OEC poised in the multiline $\mathrm{S}_{2}$ state. ${ }^{86}$ 


$$
\widehat{H}=-2 \sum_{i \neq j}^{i, j \in N} J_{i j} \widehat{S}_{l} \cdot \widehat{S}_{J}
$$

Complex 3-ox was studied by SQUID magnetometry. Similar to 2-ox, the $\chi \mathrm{T}$ value of $5.32 \mathrm{emu} \mathrm{K} \mathrm{mol}^{-1}$ at $300 \mathrm{~K}^{\text {indicates antiferro- }}$ magnetic coupling between the Mn centers (Fig. 5). $\chi \mathrm{T}$ decreases monotonically with temperature, reaching a value of $0.85 \mathrm{emu} \mathrm{K}$ $\mathrm{mol}^{-1}$ at $5 \mathrm{~K}$. The deviation from the expected $\chi \mathrm{T}$ value of $0.38 \mathrm{emu}$ $\mathrm{K} \mathrm{mol}^{-1}(S=1 / 2, g=2)$ can be attributed to the presence of thermally accessible spin excited states $S>1 / 2$. At $1.8 \mathrm{~K}$, the $\chi \mathrm{T}$ value of $0.383 \mathrm{emu} \mathrm{K} \mathrm{mol}^{-1}$ is in good agreement with the $S=1 / 2(g=2)$ ground state. To fit the susceptibility data, an isotropic exchange coupling model that consists of two edge-sharing isosceles triangles with vertices at $\mathrm{Mn}(1)-\mathrm{Mn}(2)-\mathrm{Mn}(3)$ and $\mathrm{Mn}(1)-\mathrm{Mn}(2)-\mathrm{Mn}(4)$ was employed. This model is different from that employed for 2-ox, and takes into account the pseudo-C $\mathrm{C}_{\mathrm{S}}$ symmetry of the $\left[\mathrm{Mn}_{4} \mathrm{O}_{4}\right]$ core, with different mirror planes that contain the $\operatorname{Mn}(3)-\mathrm{Mn}(4)$ and $\mathrm{Mn}(3)-\mathrm{O}(3)$ vector and bisecting the $\mathrm{Mn}(1)-\mathrm{Mn}(2)$ vector. The following parameters were used to fit the data: $J_{12}=-15.3 \mathrm{~cm}^{-1}$, $J_{13}=J_{23}=-8.9 \mathrm{~cm}^{-1}, J_{14}=J_{24}=-16.7 \mathrm{~cm}^{-1}, J_{34}=-10.6 \mathrm{~cm}^{-1}, g=1.97$. Compared to 2-ox, the smaller variation of exchange coupling constants is consistent with the smaller variation of $\mathrm{Mn}$-oxo bond distances in 3-ox. The calculated energy level diagram (Fig. S15) indicates the presence of a low-lying quartet excited states at $3-5 \mathrm{~cm}^{-1}$ (equivalent temperature of 4.3-7.2 $\mathrm{K}$ ) above the doublet ground state. Interestingly, an energy separation of 3-6 $\mathrm{cm}^{-1}$ has been reported for untreated higher plant OEC in the $S_{2}$ state. ${ }^{86-87}$

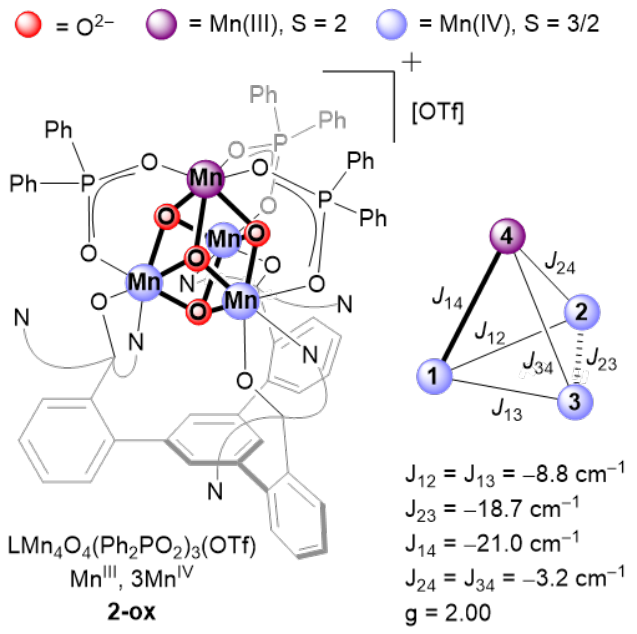

Complex 4-ox was studied by SQUID magnetometry. A higher $\chi \mathrm{T}$ value of $6.0 \mathrm{emu} \mathrm{K} \mathrm{mol}{ }^{-1}$ at $300 \mathrm{~K}$ indicates weaker antiferromagnetic coupling in 4-ox compared to 3-ox. $\chi \mathrm{T}$ decreases monotonically with temperature, reaching a value of $0.82 \mathrm{emu} \mathrm{K} \mathrm{mol}^{-1}$ at 1.8 $\mathrm{K}$, deviating significantly from the expected $\chi \mathrm{T}$ value of $0.375 \mathrm{emu}$ $\mathrm{K} \mathrm{mol}^{-1}$ for an $S=1 / 2(g=2)$ ground state. This indicates a further decreased energy separation between the ground and excited states, as expected from the weaker antiferromagnetic coupling between the Mn centers. In fact, 4-ox does not have a well-isolated spin ground state, vide infra. To fit the susceptibility data, a model identical to 3-ox was employed. The following parameters were used to fit the data: $J_{12}=-11.6 \mathrm{~cm}^{-1}, J_{13}=J_{23}=-7.2 \mathrm{~cm}^{-1}, J_{14}=J_{24}=-11.1$ $\mathrm{cm}^{-1}, J_{34}=-6.8 \mathrm{~cm}^{-1}, g=1.97$. The calculated energy level diagram indicates that the lowest doublet and quartet states are separated by $0-1 \mathrm{~cm}^{-1}$ (equivalent temperature of $1.4 \mathrm{~K}$ ) (Fig. S16). Overall, magnetic susceptibility studies indicate that the spin ladder in exchange-coupled tetranuclear $\mathrm{Mn}$ complexes is highly sensitive to small changes in structure and nature of the bridging ligands.

Variable-temperature X-band CW-EPR. EPR studies were conducted in frozen solution samples of 2-ox, 3-ox and 4-ox. At $5 \mathrm{~K}$, the EPR spectrum of 2-ox features a broad signal centered at $g=2$ featuring Mn hyperfine interactions (Fig. 6). This is consistent with the $S=1 / 2$ ground state determined from susceptibility studies. As the temperature is increased, the $g=2$ signal loses intensity until no signal is observed above $15 \mathrm{~K}$. Importantly, EPR signals originating from thermally populated spin excited states are not observed, in agreement with the predicted energy separation of $28 \mathrm{~cm}^{-1}(40 \mathrm{~K})$
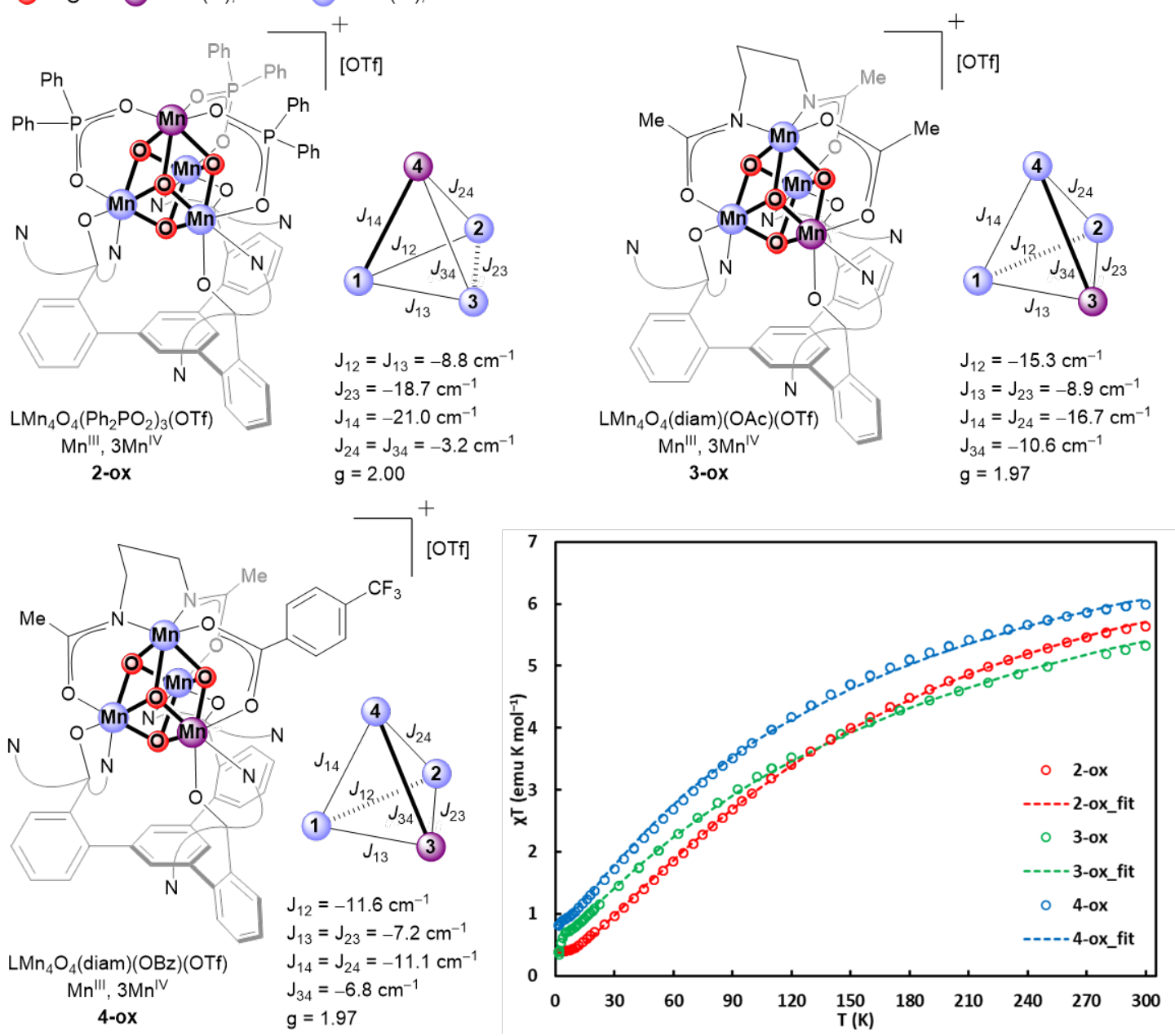

Figure 5. Exchange coupling model, fit parameters, and $\chi \mathrm{T}$ vs. $\mathrm{T}$ plot of complexes 2-ox, 3-ox, and 4-ox. For the exchange coupling models, the mirror plane of the pseudo-Cs symmetry contains the bold vector and bisects the hashed vector. 


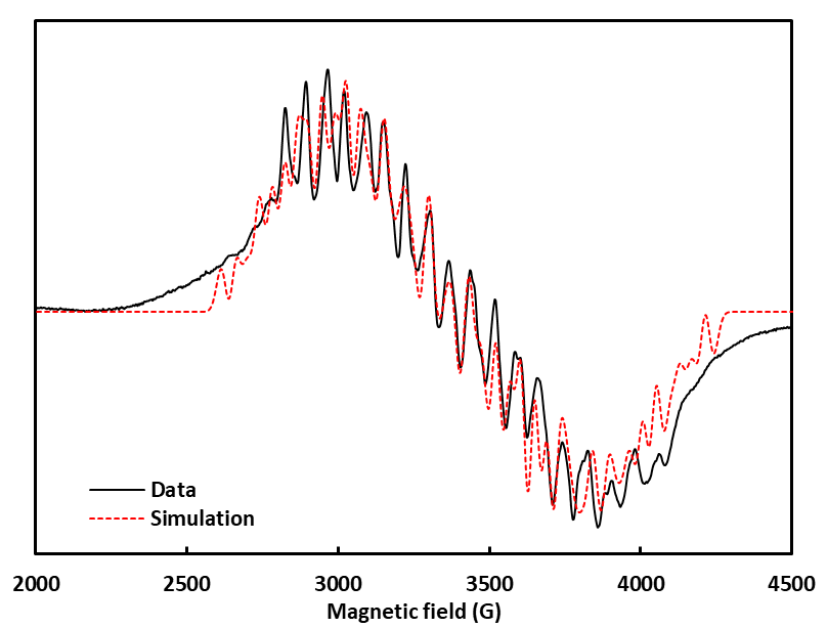

Figure 6. X-band EPR spectrum of 2-ox. Acquisition parameters: frequency $=9.64 \mathrm{MHz}$, power $=8 \mathrm{~mW}$, conversion time $=20.48 \mathrm{~ms}$, modulation amplitude $=8 \mathrm{G}$. See text for simulation parameters.

between the ground and excited states. The spectrum can be approximated by $g=[2.053,2.003,1.952], g_{\text {iso }}=2.00$ and the following ${ }^{55} \mathrm{Mn}$ hyperfine interactions $\mathrm{A}_{\text {i, }}\left(\mathrm{A}_{\mathrm{iso}}\right)_{i}: \mathrm{Mn}_{1}=[434,434,313], 394$ $\mathrm{MHz} ; \mathrm{Mn}_{2}=[293,155,245], 231 \mathrm{MHz} ; \mathrm{Mn}_{3}=[128,146,198], 157$ $\mathrm{MHz} ; \mathrm{Mn}_{4}=[134,133,72], 113 \mathrm{MHz}$. The unique, larger Mn hyperfine coupling constant $\left(394 \mathrm{MHz}\right.$ ) is consistent with the $\mathrm{Mn}^{\text {III }}$ center in 2-ox. ${ }^{88}$ The EPR spectrum of 2-ox is in stark contrast to that of the related $\left[\mathrm{Mn}_{4} \mathrm{O}_{4}\left(\mathrm{Ph}_{2} \mathrm{PO}_{2}\right)_{6}\right]^{+}$complex with a higher spin ground state $S \geq 3 / 2,{ }^{41}$ indicating that the EPR of exchange-coupled tetranuclear $\mathrm{Mn}$ complexes are highly sensitive to the Mn coordination environment, even if the core $\mathrm{Mn}_{4} \mathrm{O}_{4}$ cluster is maintained.

For the EPR spectrum of 3-ox at $5 \mathrm{~K}$, only the multiline signal centered at $g=2.0$ is discernible. As the sample is warmed, the signal at $g=2$ decreases in intensity as a signal centered at $g=4.2$ gains intensity (Fig. 7). Above $20 \mathrm{~K}$, both signals start to lose intensity due to relaxation. The signal at $g=2$ is consistent with the $S=1 / 2$ ground state determined from susceptibility studies. The $g=4.2 \mathrm{signal}$, assigned to the $S=3 / 2$ excited state of 3-ox, is highly reminiscent of the $S_{2}$ state in its HS form. The $g=2$ and the $g=4.2$ signals of the $S_{2}$ state arise from the ground states of structurally distinct species, the relative ratio of which is affected by external chemical stimuli such as $\mathrm{pH}$. As such, both EPR signals can be observed at low temperatures in a ratio that reflects the relative population of the two species. ${ }^{34}$ In the case of 3-ox, the two signals arise from different spin states of a single, structurally static species (Fig. 4). The temperature dependence of the EPR spectrum of 3-ox can be explained in terms of small differences in the Boltzmann distribution of the ground and excited states. At $5 \mathrm{~K}$, only the $S=1 / 2$ ground state is significantly populated, and the $g=2$ signal corresponds to the $|-1 / 2\rangle \rightarrow|1 / 2\rangle$ transition. As the temperature is increased, the difference in the population of the $|-1 / 2\rangle$ and the $|1 / 2\rangle$ states decrease, resulting in weaker absorption. Concurrently, as the temperature is increased, the $S=$ $3 / 2$ spin excited state is populated, and the $g=4.2$ signal corresponds to the transition within the $| \pm 3 / 2\rangle$ Kramers doublet. In contrast to 2-ox, the observation of the $g=4.2$ signal is consistent with a smaller energy separation between the ground doublet and excited quartet state in 3-ox, in agreement with the magnetic susceptibility studies. The EPR spectrum of a weakly antiferromagnetically coupled $\mathrm{Mn}^{\mathrm{III}} \mathrm{Mn}^{\text {IV }}$ dimer shows a similar temperature dependence: At $20 \mathrm{~K}$, only the $g=2$ signal is observed, but upon warming to $43 \mathrm{~K}$ and to $110 \mathrm{~K}$, a new low-field signal at $g=5$ gains intensity. ${ }^{89}$ This low-field signal has been assigned to the $S=3 / 2$ excited state. For more strongly coupled $\mathrm{Mn}^{\mathrm{III}} \mathrm{Mn}^{\mathrm{IV}}$ dimeric systems, the quartet excited state is separated from the doublet ground state by hundreds of wavenumbers and the signal corresponding to the $S=3 / 2$ excited state was not observed. ${ }^{39,90-95}$

For the EPR spectrum of 4-ox, in addition to the signal at $g=2$, other signals assignable to $S=3 / 2$ spin states were observed even at $5 \mathrm{~K}$, at $g=7.5$ and $g=5.5$. This indicates a very small energy separation between the doublet and quartet states in 4-ox, in agreement with the susceptibility studies. As the sample is warmed, the signal at $g=2$ decreases in intensity. In the low field region, the $g=7.5$ signal loses intensity upon warming, whereas the $g=5.5$ and $g=4.2$ signals gain intensity. At $15 \mathrm{~K}$, the low-field region collapses to the $g=4.2$ signal observed for 3-ox. The temperature dependence of the low field region may be explained by the presence of two distinct $S=3 / 2$ excited states.

${ }^{55} \mathrm{Mn}$ Davies ENDOR spectroscopy. To gain better understanding of the Mn hyperfine interactions (HFI) in 3-ox, ${ }^{55} \mathrm{Mn}$ Davies ENDOR spectra were collected at Q-band using the pulse sequence $\pi-t_{\mathrm{RF}}-\pi_{\mathrm{RF}}-t_{\mathrm{RF}}-\pi / 2-\tau-\pi-\tau$-echo. Spectra were collected at selected field positions along the electron spin-echo-detected EPR spectrum (ESE-EPR): $1170 \mathrm{mT}, 1200 \mathrm{mT}, 1240 \mathrm{mT}, 1270 \mathrm{mT}$, and $1300 \mathrm{mT}$ (Fig. 8a). By incorporating the ESE-EPR spectrum at D-band (130 $\mathrm{GHz}$ ) vide infra, the $g$ values were constrained to $g=[1.944,1.964$, $2.002], g_{\text {sso }}=1.97$, though it should be noted that there is no significant resolution of any individual $g$-values in the spectrum, likely due to slight inhomogeneity in the $g$-values ( $g$-strain $=0.012$ for all simulations).$^{96}$ This introduces field-dependent broadening that also causes a loss in resolution of the ${ }^{55} \mathrm{Mn}$ hyperfine structure evident in the field swept spectra as the excitation frequency is increased, a phenomenon also observed in multi-frequency EPR spectra of the $S_{2}$ state of the $\mathrm{CaMn}_{4} \mathrm{O}_{5}$ cluster of photosystem $\mathrm{II} \cdot{ }^{97} \mathrm{~A}$ global fit of the Mn hyperfine interactions incorporating the ENDOR spectra as well as the X-band CW spectrum yields the parameters listed in Table 1. Similar to 2-ox, the unique, larger Mn hyperfine coupling constant is consistent with the $\mathrm{Mn}^{\mathrm{III}}$ center in 3-ox. ${ }^{16,95}$ The Mn hyperfine coupling constants reported for 3-ox are similar in magnitude to that of the $S_{2}$ state of $T$. elongatus. ${ }^{16,86,97-98}$ Notably, ${ }^{55} \mathrm{Mn}$ ENDOR spectra for tetranuclear Mn model complexes have been hitherto absent in the literature.

ESE-EPR and electron-electron double resonance-detected NMR (EDNMR) of 3-ox were recorded at D-band (130 GHz). EDNMR employs a high-turning angle microwave pulse which concurrently excites NMR and EPR transitions rather than an RF pulse to drive NMR transitions as in ENDOR ${ }^{99}$ EDNMR offers some distinctive features compared to ENDOR, including decreased selectivity between magnetic nuclei with very different gyromagnetic ratios, decreased dependence on the species of interest to exhibit long spin lattice relaxation times, and vastly enhanced signal intensity for the same amount of acquisition time. ${ }^{100}$ However, EDNMR typically suffers from far broader lineshapes in comparison to ENDOR, as well as combination bands and multiple-quantum transitions, which can produce complex, feature-rich spectra. ${ }^{68,101}$ The EDNMR spectrum of 3-ox at $g=1.97(4.7 \mathrm{~T})$ is displayed in Figure S19. Features observed at $14 \mathrm{MHz}$ and $200 \mathrm{MHz}$ correspond to single-quantum transitions from ${ }^{14} \mathrm{~N}$ and ${ }^{1} \mathrm{H}$ nuclei of the ligand scaffold $\left({ }^{14} \mathrm{~N}\right.$ and ${ }^{1} \mathrm{H}$ Larmor frequencies at $4.7 \mathrm{~T}$ are $14.4 \mathrm{MHz}$ and $200 \mathrm{MHz}$, respectively). A large, broad peak is observed at $50 \mathrm{MHz}(\mathrm{FWHM}=48$ $\mathrm{MHz}$ ) as well as peaks at $140 \mathrm{MHz}, 150 \mathrm{MHz}$, and $170 \mathrm{MHz}$ corresponding to ${ }^{55} \mathrm{Mn}$ single-quantum transitions. In the strong coupling 

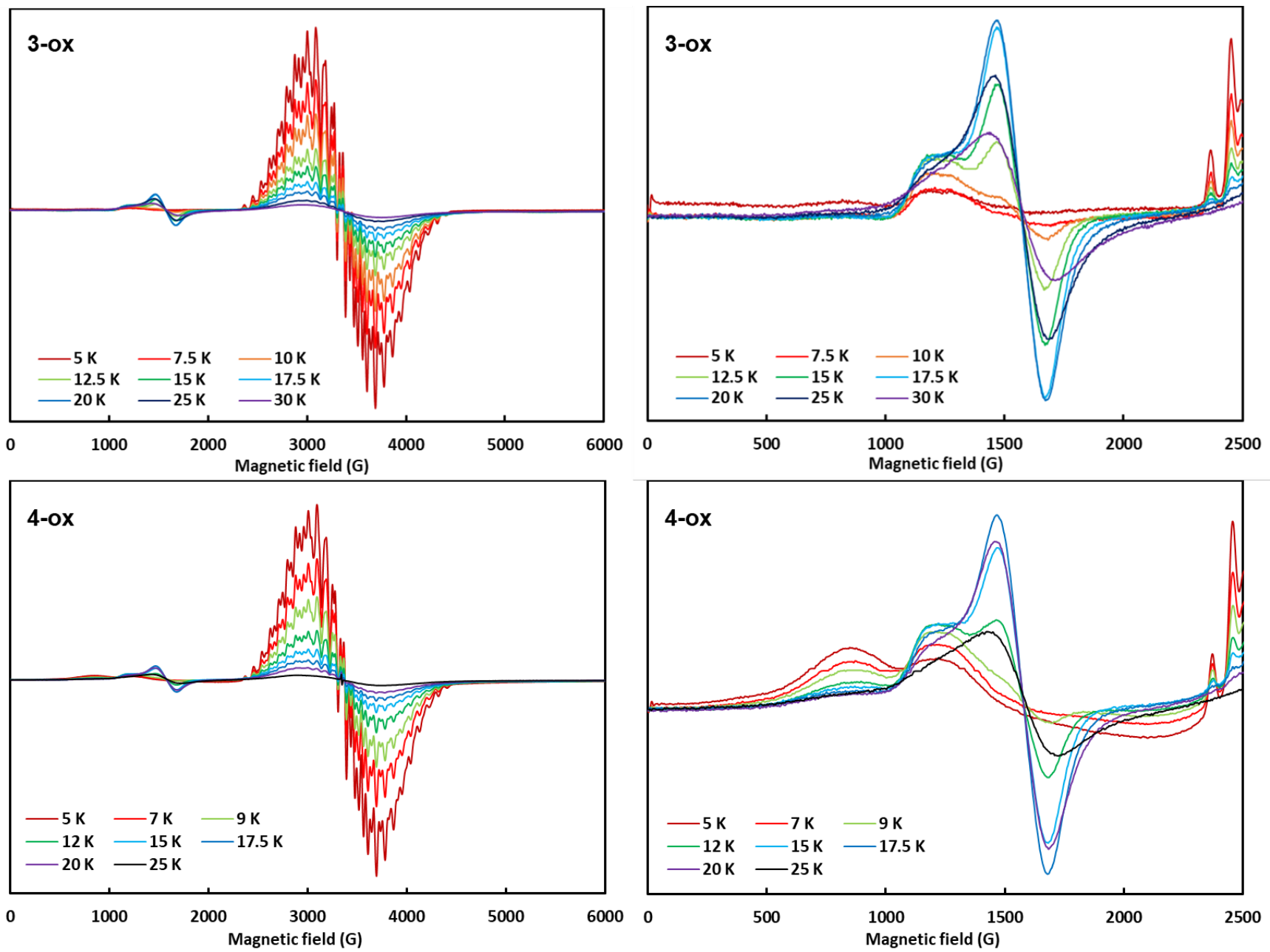

Figure 7. (Left) Variable-temperature X-band continuous-wave EPR spectra of 3-ox and 4-ox. (Right) Expanded view of the low field $(g>2)$ region.

limit, these couplings are centered at $\mathrm{A} / 2$ and split by twice the ${ }^{55} \mathrm{Mn}$ Larmor frequency (c.a. $50 \mathrm{MHz}$ at $4.7 \mathrm{~T}$ ). Based on the observed ${ }^{55} \mathrm{Mn}$ transitions, the ${ }^{55} \mathrm{Mn} \mathrm{HFI}$ are estimated in the range $180-240$ $\mathrm{MHz}$, in line with the $\mathrm{Mn}(\mathrm{IV}) \mathrm{HFI}$ measured from Q-band ${ }^{55} \mathrm{Mn}$ ENDOR. The spectral signature of the unique $\mathrm{Mn}(\mathrm{III})$ ion cannot be unambiguously assigned from the EDNMR due to multiple overlapping transitions. Nonetheless, the general agreement of the EDNMR and ENDOR data support the hyperfine assignments of 3ox. The remaining features appearing from $250-350 \mathrm{MHz}$ are assigned to ${ }^{55} \mathrm{Mn}$ double-quantum transitions.

The temperature dependence of electron spin-lattice relaxation in 3-ox was studied using the inversion-recovery sequence $(\pi-t-\pi / 2$ $-\tau-\pi-$ echo) (Fig. S18). ${ }^{102}$ Data were fit to a bi-exponential function (Eq. 2). Subscript $f$ denotes the fast relaxing process; $s$ denotes the slow process. At $3.8 \mathrm{~K}$, the relaxation time constants for the fast and slow exponential components were $1.3 \mu \mathrm{s}$ and $6.3 \mu \mathrm{s}$, respectively. Over the temperature range studied, both $\ln \left(1 / \mathrm{T}_{1}\right)$ vs. $1 / \mathrm{T}$ and $\ln \left(1 / T_{1}\right)$ vs. $\ln (T)$ are approximately linear, consistent with either an Orbach or Raman relaxation process. ${ }^{86}$ Assuming an Orbach mechanism, an energy separation of $13 \mathrm{~cm}^{-1}$ was obtained from the fast relaxing component. This value is slightly larger than the 3-5 $\mathrm{cm}^{-1}$ estimated from susceptibility studies but approximately in the same magnitude. Overall, both electron spin-lattice relaxation and magnetic susceptibility measurements support a small separation between the doublet ground state and the quartet excited state.
$M_{Z}(T)=M_{f}\left[1-2 \exp \left(-\frac{T}{T_{1 f}}\right)\right]+M_{S}\left[1-2 \exp \left(-\frac{T}{T_{1 s}}\right)\right]$

\section{DISCUSSION}

Between the optimized structures of the proposed open- and closed-cubane forms of the $\mathrm{S}_{2}$ state, $\mathrm{Mn}(4)-\mathrm{O}(5)$ and $\mathrm{Mn}(1)-\mathrm{O}(5)$ distances interchange from $1.87 \AA$ to $\sim 3.2 \AA$, tantamount to a bond breaking-reforming process (Fig. 1). This rearrangement process is accompanied by a change in the electronic structure of the $S_{2}$ state, as explained from the computed magnetic exchange coupling constants in both open and closed forms. The $g$ $=2$ and the $g=4.2$ signals of the $S_{2}$ state result from the ground states of clusters that differ significantly in geometry, the relative ratio of which is affected by external chemical stimuli. Our studies indicate that such large structural changes to the inorganic $\mathrm{CaMn}_{4} \mathrm{O}_{5}$ core of the OEC may not be necessary to perturb its electronic structure. Comparisons between the crystal structures of 2-ox, 3-ox, and 4-ox indicate only small variations in $\mathrm{Mn}$-oxo bond distances, with the longest $\mathrm{Mn}$-oxo bond in each species varying from 2.051(4) $\AA$ to 2.241(1) $\AA$. The remaining $\mathrm{Mn}-\mathrm{O}$ distances are in the range 1.831(1)-1.976(2) Å. Yet, such small geometric changes in the $\left[\mathrm{Mn}^{\mathrm{III}} \mathrm{Mn}_{3}{ }^{\mathrm{IV}} \mathrm{O}_{4}\right]$ core have a substantial effect in its electronic structure, as evident from magnetic susceptibility and EPR studies. Assigned to a thermally accessible spin excited state $S=3 / 2$, the $g=4.2$ signal in 3-ox and 4-ox is highly reminiscent of the $S_{2}$ state in its highspin form. The absence of such a signal in 2-ox indicates that spectroscopic properties of tetranuclear $\mathrm{Mn}$ complexes are highly de- 
pendent on the nature and magnitude of the magnetic exchange coupling interactions, which are finely tuned by the nature of not only bridging ligands but also terminal ligands in the immediate coordination sphere of each $\mathrm{Mn}$ ion. While the two signals observed in 3ox and 4-ox are not resulting from ground states of two different isomers, as proposed in PSII, they do correspond to low- and high-spin electronic states. As in PSII, the degrees of population of the two states are affected by different coupling schemes between the Mn centers, which arise from structural differences. Most importantly, large structural distortions are not necessary for the complete disappearance of one of the signals (the HS in this case, for 2-ox). In a previously reported $\mathrm{Mn}^{\mathrm{III}} \mathrm{Mn}_{3}{ }^{\mathrm{IV}} \mathrm{O}_{4}$ cubane with six phosphinate ligands, the LS signal completely disappears, consistent with a higher $S$ $\geq 3 / 2$ ground state. ${ }^{41}$ Furthermore, the energy separation between the doublet ground state and the first non-doublet excited state can be fine-tuned with small changes in the overall geometry of the cluster, as evidenced by the variable temperature EPR of 3-ox and 4-ox (Fig. 7). These findings suggest that geometrical changes much smaller than the ones proposed for PSII with respect to the metal and oxo/hydroxo motifs could have substantial effects on the EPR signals. Therefore, the deduction of the geometry of OEC S-state intermediates based on EPR spectroscopic features need to be complemented with appropriate structural determination. Given that in the present series of compounds, even a change in the nature of a single carboxylate ligand affects the state energies and EPR signals, it is expected that features such as the protonation state of aquo ligands, bridging oxos, and nearby His residues will greatly affect the electronic structure of the OEC.

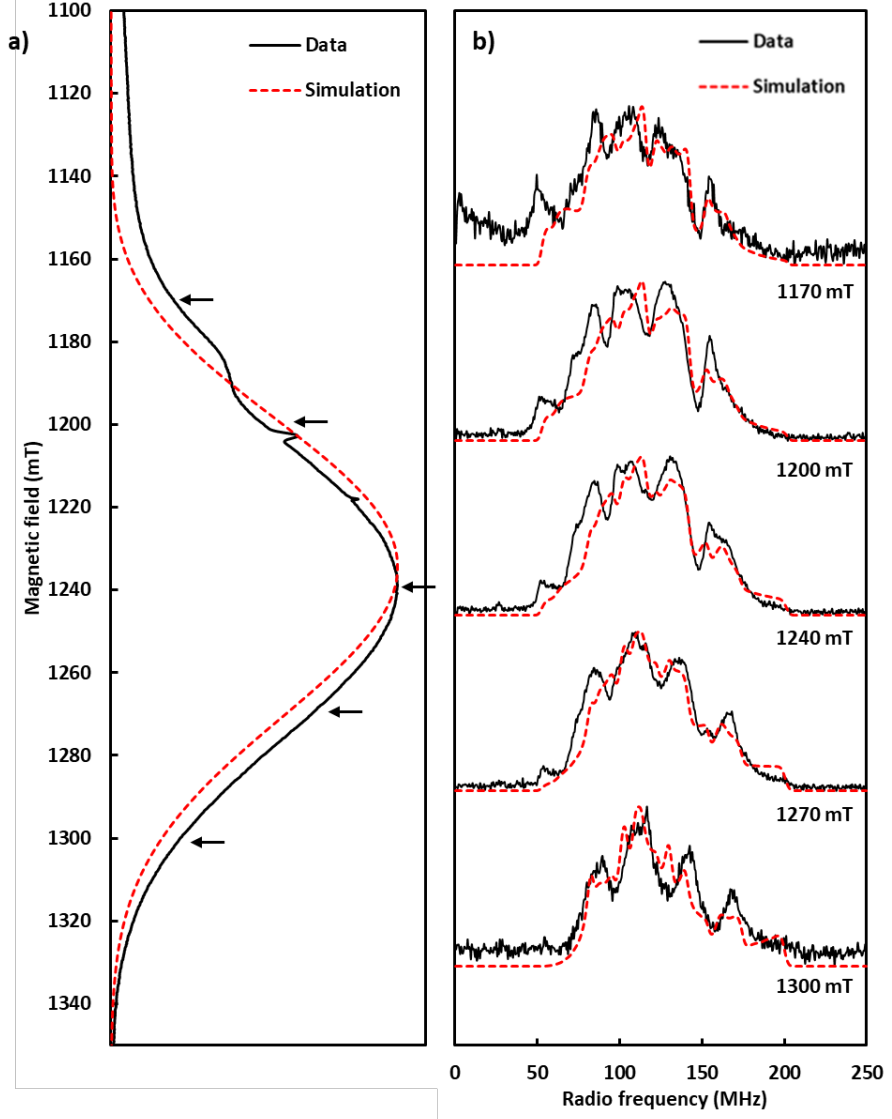

Table 1. Summary of the effective $g$ and ${ }^{55} \mathrm{Mn}$ HFI tensors for 3-ox, and the $S_{2}$ states of T. elongatus and spinach PSII. ${ }^{86,97}$ Note: all hyperfine tensor frames collinear with $g$-tensor frame.

\begin{tabular}{ccccccc}
\hline & & $g$ & \multicolumn{4}{c}{$\mathrm{A}_{\mathrm{i}}(\mathrm{MHz})$} \\
\cline { 3 - 6 } & & & $\mathrm{A}_{1}$ & $\mathrm{~A}_{2}$ & $\mathrm{~A}_{3}$ & $\mathrm{~A}_{4}$ \\
\hline 3-ox & $\mathrm{x}$ & 1.944 & 376 & 233 & 253 & 193 \\
& $\mathrm{y}$ & 1.964 & 297 & 198 & 283 & 222 \\
& $\mathrm{z}$ & 2.002 & 272 & 260 & 149 & 131 \\
& iso & 1.970 & 315 & 230 & 228 & 198 \\
\hline T. elongatus & $\mathrm{x}$ & 1.971 & 350 & 249 & 202 & 148 \\
& $\mathrm{y}$ & 1.948 & 310 & 227 & 182 & 162 \\
& $\mathrm{z}$ & 1.985 & 275 & 278 & 240 & 263 \\
& iso & 1.968 & 312 & 251 & 208 & 191 \\
\hline Spinach & $\mathrm{x}$ & 1.997 & 310 & 235 & 185 & 170 \\
& $\mathrm{y}$ & 1.970 & 310 & 235 & 185 & 170 \\
& $\mathrm{z}$ & 1.965 & 275 & 275 & 245 & 240 \\
& iso & 1.977 & 298 & 248 & 205 & 193 \\
\hline
\end{tabular}

In conclusion, a series of $\mathrm{Mn}^{\mathrm{III}} \mathrm{Mn}_{3}{ }^{\mathrm{IV}} \mathrm{O}_{4}$ cuboidal complexes has been synthesized and characterized by XRD, electrochemistry, XAS, SQUID magnetometry, variable temperature CW-EPR, and pulsedEPR. To our knowledge this is the first set of experimental studies that directly addresses the effect of systematic changes of supporting ligands on the EPR behavior of clusters in the redox state of the $\mathrm{S}_{2}$
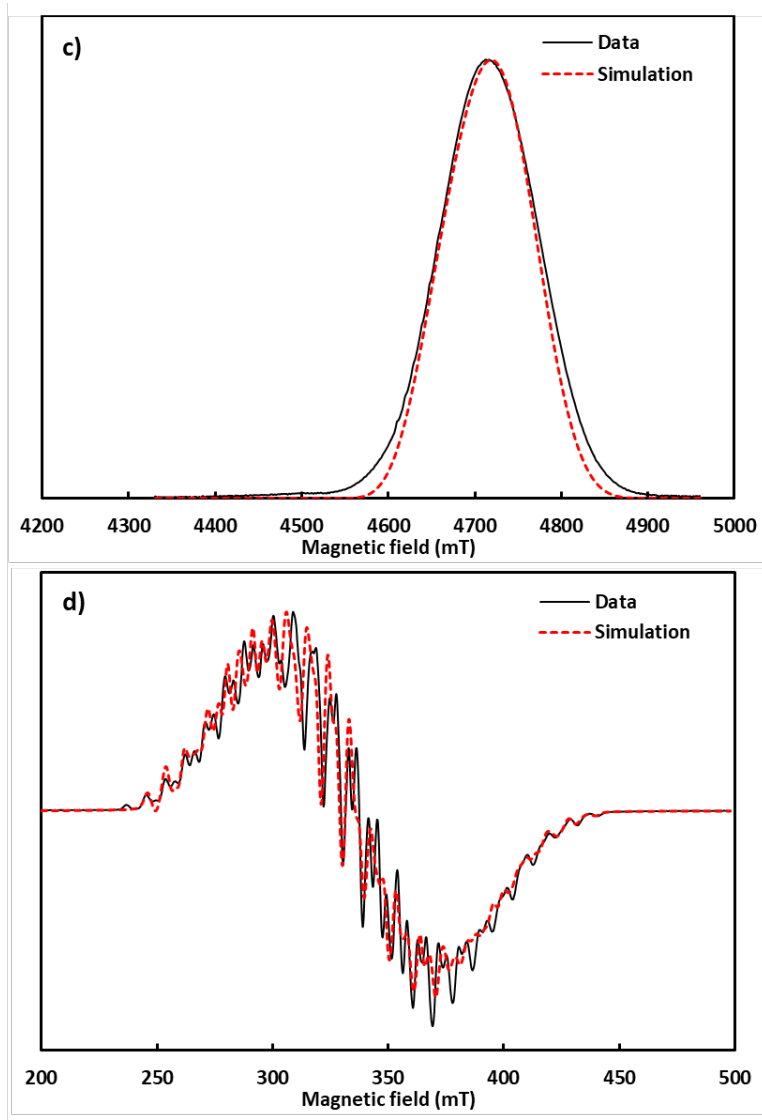

Figure 8. Experimental spectra of 3-ox (black traces) and simulation (dashed red traces). a) Q-band electron spin echo (ESE) EPR. b) Q-band ${ }^{55}$ Mn Davies ENDOR recorded at five magnetic field positions indicated in a). Acquisition parameters: Temp. $=3.8 \mathrm{~K}, \mathrm{MW}$ freq. $=34.115 \mathrm{GHz}, \pi_{\mathrm{MW}}=40$ $\mathrm{ns}, \pi_{\mathrm{RF}}=3 \mu \mathrm{s}, \mathrm{t}_{\mathrm{RF}}=2 \mu \mathrm{s}, \tau=400 \mathrm{~ns}$. c) D-band ESE-EPR. Acquisition parameters: Temp. $=5.2 \mathrm{~K}$, MW freq. $=130 \mathrm{GHz}, \pi_{\mathrm{MW}}=90 \mathrm{~ns}, \tau=300 \mathrm{~ns}$. d) Xband CW EPR. Acquisition parameters: Temp. $=5 \mathrm{~K}$, MW freq. $=9.359 \mathrm{MHz}$, power $=2 \mathrm{~mW}$, modulation amplitude $=4 \mathrm{G}$. See Table 1 for global fit parameters. 
state of the OEC. With implications in the interpretation of the OEC spectroscopic properties, our benchmarking results show that the electronic structure of tetranuclear $\mathrm{Mn}$ complexes is highly sensitive to small geometric changes and the nature of the bridging ligands. Even in the absence of large oxo movements proposed to account for the HS and LS signals of the OEC, we find that the EPR feature of essentially isostructural compounds can move from LS to a mixture of LS and HS to HS signals. Therefore, interpretation of EPR signals in terms of structural implications must be done very cautiously. Ideally, complementary structural information will be obtained to corroborate spectroscopic assignments.

\section{ASSOCIATED CONTENT}

Supporting Information. Experimental procedures and characterization. This material is available free of charge via the Internet at http://pubs.acs.org.

\section{AUTHOR INFORMATION}

\section{Corresponding Author}

*rdbritt@ucdavis.edu

*agapie@caltech.edu

\section{Notes}

The authors declare no competing financial interest.

\section{ACKNOWLEDGMENT}

This research was supported by the NIH (R01-GM102687B), the Dreyfus Teacher-Scholar Program (T.A.), Dow Next Generation Educator (instrumentation), NSF-1531940 (Caltech EPR facility), the Division of Chemical Sciences, Geosciences, and Biosciences (R.D.B. grant DESC0007203) of the Office of Basic Energy Sciences of the U.S. Department of Energy. Part of this work (XAS data collection) was carried out at Stanford Synchrotron Radiation Lightsource, SLAC National Accelerator Laboratory, supported by the U.S. Department of Energy, Office of Science, Office of Basic Energy Sciences under Contract No. DEAC02-76SF00515. XAS studies were performed with support of the Office of Science, OBES, Division of Chemical Sciences, Geosciences, and Biosciences (CSGB) of the DOE under contract no. DE-AC0205CH11231 (J.Y.). We thank Dr. Michael K. Takase and Mr. Lawrence M. Henling for assistance with X-ray crystallography; Dr. Ignacio B. Martini for SQUID magnetometry.

\section{REFERENCES}

(1) Shen, J.-R., The Structure of Photosystem II and the Mechanism of Water Oxidation in Photosynthesis. Annu. Rev. Plant Biol.2015, 66, 23.

(2) Yano, J.; Yachandra, V., $\mathrm{Mn}_{4} \mathrm{Ca}$ Cluster in Photosynthesis: Where and How Water is Oxidized to Dioxygen. Chem. Rev. 2014, 114, 4175.

(3) Cox, N.; Pantazis, D. A.; Neese, F.; Lubitz, W., Biological Water Oxidation. Acc. Chem. Res. 2013, 46, 1588.

(4) Oyala, P. H.; Stich, T. A.; Debus, R. J.; Britt, R. D., Ammonia Binds to the Dangler Manganese of the Photosystem II Oxygen-Evolving Complex. J. Am. Chem. Soc. 2015, 137, 8829.

(5) Siegbahn, P. E. M., Structures and Energetics for $\mathrm{O}_{2}$ Formation in Photosystem II. Acc. Chem. Res. 2009, 42, 1871.

(6) Oyala, P. H.; Stich, T. A.; Stull, J. A.; Yu, F.; Pecoraro, V. L.; Britt, R. D., Pulse Electron Paramagnetic Resonance Studies of the Interaction of Methanol with the $\mathrm{S}_{2}$ State of the $\mathrm{Mn}_{4} \mathrm{O}_{5} \mathrm{Ca}$ Cluster of Photosystem II. Biochemistry2014, 53, 7914.

(7) Pérez Navarro, M.; Ames, W. M.; Nilsson, H.; Lohmiller, T.; Pantazis, D. A.; Rapatskiy, L.; Nowaczyk, M. M.; Neese, F.; Boussac, A.; Messinger, J.; Lubitz, W.; Cox, N., Ammonia binding to the oxygenevolving complex of photosystem II identifies the solvent-exchangeable oxygen bridge ( $\mu$-oxo) of the manganese tetramer. Proc. Nat. Acad. Sci. 2013, 110, 15561 .
(8) Rapatskiy, L.; Cox, N.; Savitsky, A.; Ames, W. M.; Sander, J.; Nowaczyk, M. M.; Rögner, M.; Boussac, A.; Neese, F.; Messinger, J.; Lubitz, W., Detection of the Water-Binding Sites of the OxygenEvolving Complex of Photosystem II Using W-Band ${ }^{17} \mathrm{O}$ ElectronElectron Double Resonance-Detected NMR Spectroscopy. J. Am. Chem. Soc. 2012, 134, 16619.

(9) Boussac, A.; Rutherford, A. W., Comparative study of the g=4.1 EPR signals in the $S_{2}$ state of photosystem II. Biochim. Biophys. Acta $2000,1457,145$.

(10) Haddy, A.; Lakshmi, K. V.; Brudvig, G. W.; Frank, H. A., Q-Band EPR of the $S_{2}$ State of Photosystem II Confirms an $S=5 / 2$ Origin of the X-Band g=4.1 Signal. Biophys. J.2004, 87, 2885.

(11) Boussac, A.; Un, S.; Horner, O.; Rutherford, A. W., High-Spin States $(S \geq 5 / 2)$ of the Photosystem II Manganese Complex. Biochemistry 1998, 37, 4001.

(12) Britt, R. D.; Lorigan, G. A.; Sauer, K.; Klein, M. P.; Zimmermann, J.-L., The $g=2$ multiline EPR signal of the $S_{2}$ state of the photosynthetic oxygen-evolving complex originates from a ground spin state. Biochim. Biophys. Acta - Bioenergetics 1992, 1140, 95.

(13) Kim, D. H.; Britt, R. D.; Klein, M. P.; Sauer, K., The manganese site of the photosynthetic oxygen-evolving complex probed by EPR spectroscopy of oriented photosystem II membranes: the $\mathrm{g}=4$ and $\mathrm{g}=$ 2 multiline signals. Biochemistry 1992, 31, 541.

(14) Dismukes, G. C.; Siderer, Y., Intermediates of a polynuclear manganese center involved in photosynthetic oxidation of water. Proc. Nat. Acad. Sci. 1981, 78, 274.

(15) Krewald, V.; Retegan, M.; Cox, N.; Messinger, J.; Lubitz, W.; DeBeer, S.; Neese, F.; Pantazis, D. A., Metal oxidation states in biological water splitting. Chem. Sci.2015, 6, 1676.

(16) Peloquin, J. M.; Campbell, K. A.; Randall, D. W.; Evanchik, M. A.; Pecoraro, V. L.; Armstrong, W. H.; Britt, R. D., ${ }^{55} \mathrm{Mn}$ ENDOR of the $\mathrm{S}_{2-}$ State Multiline EPR Signal of Photosystem II: Implications on the Structure of the Tetranuclear Mn Cluster. J. Am. Chem. Soc. 2000, 122, 10926.

(17) Cox, N.; Retegan, M.; Neese, F.; Pantazis, D. A.; Boussac, A.; Lubitz, W., Electronic structure of the oxygen-evolving complex in photosystem II prior to O-O bond formation. Science 2014, 345, 804.

(18) DeRose, V. J.; Latimer, M. J.; Zimmermann, J.-L.; Mukerji, I.; Yachandra, V. K.; Sauer, K.; Klein, M. P., Fluoride substitution in the Mn cluster from Photosystem II: EPR and X-ray absorption spectroscopy studies. Chem. Phys. 1995, 194, 443.

(19) Lohmiller, T.; Krewald, V.; Navarro, M. P.; Retegan, M.; Rapatskiy, L.; Nowaczyk, M. M.; Boussac, A.; Neese, F.; Lubitz, W.; Pantazis, D. A.; Cox, N., Structure, ligands and substrate coordination of the oxygen-evolving complex of photosystem II in the $S_{2}$ state: a combined EPR and DFT study. Phys. Chem. Chem. Phys. 2014, 16, 11877.

(20) Glöckner, C.; Kern, J.; Broser, M.; Zouni, A.; Yachandra, V.; Yano, J., Structural Changes of the Oxygen-evolving Complex in Photosystem II during the Catalytic Cycle. J. Biol. Chem. 2013, 288, 22607.

(21) Lohmiller, T.; Ames, W.; Lubitz, W.; Cox, N.; Misra, S. K., EPR Spectroscopy and the Electronic Structure of the Oxygen-Evolving Complex of Photosystem II. Appl. Magn. Reson. 2013, 44, 691.

(22) Pantazis, D. A.; Ames, W.; Cox, N.; Lubitz, W.; Neese, F., Two Interconvertible Structures that Explain the Spectroscopic Properties of the Oxygen-Evolving Complex of Photosystem II in the $\mathrm{S}_{2}$ State. Angew. Chem. Int. Ed. 2012, 51, 9935.

(23) Horner, O.; Rivière, E.; Blondin, G.; Un, S.; Rutherford, A. W.; Girerd, J.-J.; Boussac, A., SQUID Magnetization Study of the InfraredInduced Spin Transition in the $S_{2}$ State of Photosystem II: Spin Value Associated with the $\mathrm{g}=4.1 \mathrm{EPR}$ Signal. J. Am. Chem. Soc. 1998, 120, 7924.

(24) Bovi, D.; Narzi, D.; Guidoni, L., The $S_{2}$ State of the OxygenEvolving Complex of Photosystem II Explored by QM/MM Dynamics: Spin Surfaces and Metastable States Suggest a Reaction Path Towards the $\mathrm{S}_{3}$ State. Angew. Chem. Int. Ed. 2013, 52, 11744. 
(25) Vinyard, D. J.; Khan, S.; Askerka, M.; Batista, V. S.; Brudvig, G. W., Energetics of the $S_{2}$ State Spin Isomers of the Oxygen-Evolving Complex of Photosystem II. J. Phys. Chem. B 2017, 121, 1020.

(26) Suga, M.; Akita, F.; Sugahara, M.; Kubo, M.; Nakajima, Y.; Nakane, T.; Yamashita, K.; Umena, Y.; Nakabayashi, M.; Yamane, T.; Nakano, T.; Suzuki, M.; Masuda, T.; Inoue, S.; Kimura, T.; Nomura, T.; Yonekura, S.; Yu, L.-J.; Sakamoto, T.; Motomura, T.; Chen, J.-H.; Kato, Y.; Noguchi, T.; Tono, K.; Joti, Y.; Kameshima, T.; Hatsui, T.; Nango, E.; Tanaka, R.; Naitow, H.; Matsuura, Y.; Yamashita, A.; Yamamoto, M.; Nureki, O.; Yabashi, M.; Ishikawa, T.; Iwata, S.; Shen, J.-R., Lightinduced structural changes and the site of $\mathrm{O}=\mathrm{O}$ bond formation in PSII caught by XFEL. Nature 2017, 543, 131.

(27) Young, I. D.; Ibrahim, M.; Chatterjee, R.; Gul, S.; Fuller, F. D.; Koroidov, S.; Brewster, A. S.; Tran, R.; Alonso-Mori, R.; Kroll, T.; Michels-Clark, T.; Laksmono, H.; Sierra, R. G.; Stan, C. A.; Hussein, R.; Zhang, M.; Douthit, L.; Kubin, M.; de Lichtenberg, C.; Vo Pham, L.; Nilsson, H.; Cheah, M. H.; Shevela, D.; Saracini, C.; Bean, M. A.; Seuffert, I.; Sokaras, D.; Weng, T.-C.; Pastor, E.; Weninger, C.; Fransson, T.; Lassalle, L.; Bräuer, P.; Aller, P.; Docker, P. T.; Andi, B.; Orville, A. M.; Glownia, J. M.; Nelson, S.; Sikorski, M.; Zhu, D.; Hunter, M. S.; Lane, T. J.; Aquila, A.; Koglin, J. E.; Robinson, J.; Liang, M.; Boutet, S.; Lyubimov, A. Y.; Uervirojnangkoorn, M.; Moriarty, N. W.; Liebschner, D.; Afonine, P. V.; Waterman, D. G.; Evans, G.; Wernet, P.; Dobbek, H.; Weis, W. I.; Brunger, A. T.; Zwart, P. H.; Adams, P. D.; Zouni, A.; Messinger, J.; Bergmann, U.; Sauter, N. K.; Kern, J.; Yachandra, V. K.; Yano, J., Structure of photosystem II and substrate binding at room temperature. Nature 2016, 540, 453.

(28) Kern, J.; Tran, R.; Alonso-Mori, R.; Koroidov, S.; Echols, N.; Hattne, J.; Ibrahim, M.; Gul, S.; Laksmono, H.; Sierra, R. G.; Gildea, R. J.; Han, G.; Hellmich, J.; Lassalle-Kaiser, B.; Chatterjee, R.; Brewster, A. S.; Stan, C. A.; Glöckner, C.; Lampe, A.; DiFiore, D.; Milathianaki, D.; Fry, A. R.; Seibert, M. M.; Koglin, J. E.; Gallo, E.; Uhlig, J.; Sokaras, D.; Weng, T.-C.; Zwart, P. H.; Skinner, D. E.; Bogan, M. J.; Messerschmidt, M.; Glatzel, P.; Williams, G. J.; Boutet, S.; Adams, P. D.; Zouni, A.; Messinger, J.; Sauter, N. K.; Bergmann, U.; Yano, J.; Yachandra, V. K., Taking snapshots of photosynthetic water oxidation using femtosecond X-ray diffraction and spectroscopy. Nat. Commun. 2014, 5, 4371.

(29) Suga, M.; Akita, F.; Hirata, K.; Ueno, G.; Murakami, H.; Nakajima, Y.; Shimizu, T.; Yamashita, K.; Yamamoto, M.; Ago, H.; Shen, J.-R., Native structure of photosystem II at $1.95 \AA$ resolution viewed by femtosecond X-ray pulses. Nature 2014, 517, 99.

(30) Kern, J.; Alonso-Mori, R.; Tran, R; Hattne, J.; Gildea, R. J.; Echols, N.; Glöckner, C.; Hellmich, J.; Laksmono, H.; Sierra, R. G.; Lassalle-Kaiser, B.; Koroidov, S.; Lampe, A.; Han, G.; Gul, S.; DiFiore, D.; Milathianaki, D.; Fry, A. R; Miahnahri, A.; Schafer, D. W.; Messerschmidt, M.; Seibert, M. M.; Koglin, J. E.; Sokaras, D.; Weng, T.C.; Sellberg, J.; Latimer, M. J.; Grosse-Kunstleve, R. W.; Zwart, P. H.; White, W. E.; Glatzel, P.; Adams, P. D.; Bogan, M. J.; Williams, G. J.; Boutet, S.; Messinger, J.; Zouni, A.; Sauter, N. K.; Yachandra, V. K.; Bergmann, U.; Yano, J., Simultaneous Femtosecond X-ray Spectroscopy and Diffraction of Photosystem II at Room Temperature. Science 2013, 340, 491.

(31) Kupitz, C.; Basu, S.; Grotjohann, I.; Fromme, R.; Zatsepin, N. A.; Rendek, K. N.; Hunter, M. S.; Shoeman, R. L.; White, T. A.; Wang, D.; James, D.; Yang, J.-H.; Cobb, D. E.; Reeder, B.; Sierra, R. G.; Liu, H.; Barty, A.; Aquila, A. L.; Deponte, D.; Kirian, R. A.; Bari, S.; Bergkamp, J. J.; Beyerlein, K. R.; Bogan, M. J.; Caleman, C.; Chao, T.-C.; Conrad, C. E.; Davis, K. M.; Fleckenstein, H.; Galli, L.; Hau-Riege, S. P.; Kassemeyer, S.; Laksmono, H.; Liang, M.; Lomb, L.; Marchesini, S.; Martin, A. V.; Messerschmidt, M.; Milathianaki, D.; Nass, K.; Ros, A.; Roy-Chowdhury, S.; Schmidt, K.; Seibert, M.; Steinbrener, J.; Stellato, F.; Yan, L.; Yoon, C.; Moore, T. A.; Moore, A. L.; Pushkar, Y.; Williams, G. J.; Boutet, S.; Doak, R. B.; Weierstall, U.; Frank, M.; Chapman, H. N.; Spence, J. C. H.; Fromme, P., Serial time-resolved crystallography of photosystem II using a femtosecond X-ray laser. Nature 2014, 513, 261.
(32) Sauter, N. K.; Echols, N.; Adams, P. D.; Zwart, P. H.; Kern, J.; Brewster, A. S.; Koroidov, S.; Alonso-Mori, R.; Zouni, A.; Messinger, J.; Bergmann, U.; Yano, J.; Yachandra, V. K., No observable conformational changes in PSII. Nature 2016, 533, E1.

(33) Boussac, A.; Rutherford, A. W.; Sugiura, M., Electron transfer pathways from the $\mathrm{S}_{2}$-states to the $\mathrm{S}_{3}$-states either after a $\mathrm{Ca}^{2+} / \mathrm{Sr}^{2+}$ or a $\mathrm{Cl}^{-} / \mathrm{I}^{-}$exchange in Photosystem II from Thermosynechococcus elongatus. Biochim. Biophys. Acta - Bioenergetics 2015, 1847, 576.

(34) Boussac, A.; Ugur, I.; Marion, A.; Sugiura, M.; Kaila, V. R. I.; Rutherford, A. W., The low spin - high spin equilibrium in the $\mathrm{S}_{2}$-state of the water oxidizing enzyme. Biochim. Biophys. Acta - Bioenergetics 2018, 1859, 342.

(35) Ames, W.; Pantazis, D. A.; Krewald, V.; Cox, N.; Messinger, J.; Lubitz, W.; Neese, F., Theoretical Evaluation of Structural Models of the $\mathrm{S}_{2}$ State in the Oxygen Evolving Complex of Photosystem II: Protonation States and Magnetic Interactions. J. Am. Chem. Soc. 2011, 133, 19743.

(36) Liang, W.; Latimer, M. J.; Dau, H.; Roelofs, T. A.; Yachandra, V. K.; Sauer, K.; Klein, M. P., Correlation between Structure and Magnetic Spin State of the Manganese Cluster in the Oxygen-Evolving Complex of Photosystem II in the $\mathrm{S}_{2}$ State: Determination by X-ray Absorption Spectroscopy. Biochemistry 1994, 33, 4923.

(37) Chatterjee, R.; Han, G.; Kern, J.; Gul, S.; Fuller, F. D.; Garachtchenko, A.; Young, I. D.; Weng, T.-C.; Nordlund, D.; AlonsoMori, R.; Bergmann, U.; Sokaras, D.; Hatakeyama, M.; Yachandra, V. K.; Yano, J., Structural changes correlated with magnetic spin state isomorphism in the $\mathrm{S}_{2}$ state of the $\mathrm{Mn}_{4} \mathrm{CaO}_{5}$ cluster in the oxygenevolving complex of photosystem II. Chem. Sci. 2016, 7, 5236.

(38) Paul, S.; Neese, F.; Pantazis, D. A., Structural models of the biological oxygen-evolving complex: achievements, insights, and challenges for biomimicry. Green Chem. 2017, 19, 2309.

(39) Mukhopadhyay, S.; Mandal, S. K.; Bhaduri, S.; Armstrong, W. H., Manganese Clusters with Relevance to Photosystem II. Chem. Rev. 2004, 104, 3981.

(40) Mullins, C. S.; Pecoraro, V. L., Reflections on small molecule manganese models that seek to mimic photosynthetic water oxidation chemistry. Coord. Chem. Rev. 2008, 252, 416.

(41) Ruettinger, W. F.; Ho, D. M.; Dismukes, G. C., Protonation and Dehydration Reactions of the $\mathrm{Mn}_{4} \mathrm{O}_{4} \mathrm{~L}_{6}$ Cubane and Synthesis and Crystal Structure of the Oxidized Cubane $\left[\mathrm{Mn}_{4} \mathrm{O}_{4} \mathrm{~L}_{6}\right]^{+}$: A Model for the Photosynthetic Water Oxidizing Complex. Inorg. Chem. 1999, 38, 1036.

(42) Dubé, C. E.; Sessoli, R.; Hendrich, M. P.; Gatteschi, D.; Armstrong, W. H., A Spin Topological Model for the $g=4.1 \mathrm{~S}_{2}$ State Photosystem II Water Oxidase Manganese Aggregate. J. Am. Chem. Soc. 1999, 121, 3537.

(43) Blondin, G.; Davydov, R.; Philouze, C.; Charlot, M.-F.; Styring, S.; Akermark, B.; Girerd, J.-J.; Boussac, A., Electron paramagnetic resonance study of the $S=1 / 2$ ground state of a radiolysis-generated manganese(III)-trimanganese(IV) form of $\left[\mathrm{Mn}^{\mathrm{IV} 4} \mathrm{O}_{6}(\text { bipy })_{6}\right]^{4+}$ (bipy=2,2'-bipyridine). Comparison with the photosynthetic Oxygen Evolving Complex. J. Chem. Soc., Dalton Trans. 1997, 4069.

(44) Zhang, C.; Chen, C.; Dong, H.; Shen, J.-R.; Dau, H.; Zhao, J., A synthetic Mn4Ca-cluster mimicking the oxygen-evolving center of photosynthesis. Science 2015, 348, 690.

(45) Shoji, M.; Isobe, H.; Shen, J.-R.; Yamaguchi, K., Geometric and electronic structures of the synthetic $\mathrm{Mn}_{4} \mathrm{CaO}_{4}$ model compound mimicking the photosynthetic oxygen-evolving complex. Phys. Chem. Chem. Phys. 2016, 18, 11330.

(46) Paul, S.; Cox, N.; Pantazis, D. A., What Can We Learn from a Biomimetic Model of Nature's Oxygen-Evolving Complex? Inorg. Chem. 2017, 56, 3875.

(47) Dubé, C. E.; Mukhopadhyay, S.; Bonitatebus, P. J.; Staples, R. J.; Armstrong, W. H., Tuning Tetranuclear Manganese-Oxo Core Electronic Properties: Adamantane-Shaped Complexes Synthesized by Ligand Exchange. Inorg. Chem. 2005, 44, 5161. 
(48) Krewald, V.; Neese, F.; Pantazis, D. A., On the Magnetic and Spectroscopic Properties of High-Valent $\mathrm{Mn}_{3} \mathrm{CaO}_{4}$ Cubanes as Structural Units of Natural and Artificial Water-Oxidizing Catalysts. J. Am. Chem. Soc. 2013, 135, 5726.

(49) Mukherjee, S.; Stull, J. A.; Yano, J.; Stamatatos, T. C.; Pringouri, K.; Stich, T. A.; Abboud, K. A.; Britt, R. D.; Yachandra, V. K.; Christou, G., Synthetic model of the asymmetric $\left[\mathrm{Mn}_{3} \mathrm{CaO}_{4}\right]$ cubane core of the oxygen-evolving complex of photosystem II. Proc. Nat. Acad. Sci. 2012, $109,2257$.

(50) Hendrickson, D. N.; Christou, G.; Schmitt, E. A.; Libby, E.; Bashkin, J. S.; Wang, S.; Tsai, H. L.; Vincent, J. B.; Boyd, P. D. W., Photosynthetic water oxidation center: spin frustration in distorted cubane $\mathrm{Mn}^{\mathrm{IV}} \mathrm{Mn}^{\mathrm{III} 3}$ model complexes. J. Am. Chem. Soc. 1992, 114, 2455.

(51) Hewitt, I. J.; Tang, J.-K.; Madhu, N. T.; Clérac, R.; Buth, G.; Anson, C. E.; Powell, A. K, A series of new structural models for the OEC in photosystem II. Chem. Commun. 2006, 2650.

(52) Koumousi, E. S.; Mukherjee, S.; Beavers, C. M.; Teat, S. J.; Christou, G.; Stamatatos, T. C., Towards models of the oxygen-evolving complex (OEC) of photosystem II: a $\mathrm{Mn}_{4} \mathrm{Ca}$ cluster of relevance to low oxidation states of the OEC. Chem. Commun. 2011, 47, 11128.

(53) Tsui, E. Y.; Tran, R.; Yano, J.; Agapie, T., Redox-inactive metals modulate the reduction potential in heterometallic manganese-oxido clusters. Nat. Chem. 2013, 5, 293.

(54) Tsui, E. Y.; Agapie, T., Reduction potentials of heterometallic manganese-oxido cubane complexes modulated by redox-inactive metals. Proc. Nat. Acad. Sci. 2013, 110, 10084.

(55) Kanady, J. S.; Tran, R.; Stull, J. A.; Lu, L.; Stich, T. A.; Day, M. W.; Yano, J.; Britt, R. D.; Agapie, T., Role of oxido incorporation and ligand lability in expanding redox accessibility of structurally related $\mathrm{Mn}_{4}$ clusters. Chem. Sci. 2013, 4, 3986.

(56) Kanady, J. S.; Lin, P.-H.; Carsch, K. M.; Nielsen, R. J.; Takase, M. K.; Goddard, W. A.; Agapie, T., Toward Models for the Full OxygenEvolving Complex of Photosystem II by Ligand Coordination To Lower the Symmetry of the $\mathrm{Mn}_{3} \mathrm{CaO}_{4}$ Cubane: Demonstration That Electronic Effects Facilitate Binding of a Fifth Metal. J. Am. Chem. Soc. 2014, 136, 14373.

(57) Kanady, J. S.; Mendoza-Cortes, J. L.; Tsui, E. Y.; Nielsen, R. J.; Goddard, W. A.; Agapie, T., Oxygen Atom Transfer and Oxidative Water Incorporation in Cuboidal $\mathrm{Mn}_{3} \mathrm{MO}_{\mathrm{n}}$ Complexes Based on Synthetic, Isotopic Labeling, and Computational Studies. J. Am. Chem. Soc. 2013, 135, 1073.

(58) Lin, P.-H.; Tsui, E. Y.; Habib, F.; Murugesu, M.; Agapie, T., Effect of the Mn Oxidation State on Single-Molecule-Magnet Properties: $\mathrm{Mn}^{\text {III }}$ vs $\mathrm{Mn}^{\mathrm{IV}}$ in Biologically Inspired $\mathrm{DyMn}_{3} \mathrm{O}_{4}$ Cubanes. Inorg. Chem. 2016, 55, 6095 .

(59) Han, Z.; Horak, K. T.; Lee, H. B.; Agapie, T., Tetranuclear Manganese Models of the OEC Displaying Hydrogen Bonding Interactions: Application to Electrocatalytic Water Oxidation to Hydrogen Peroxide. J. Am. Chem. Soc. 2017, 139, 9108.

(60) Lee, H. B.; Tsui, E. Y.; Agapie, T., A CaMn${ }_{4} \mathrm{O}_{2}$ model of the biological oxygen evolving complex: synthesis via cluster expansion on a low symmetry ligand. Chem. Commun. 2017, 53, 6832.

(61) Ruettinger, W. F.; Campana, C.; Dismukes, G. C., Synthesis and Characterization of $\mathrm{Mn}_{4} \mathrm{O}_{4} \mathrm{~L}_{6}$ Complexes with Cubane-like Core Structure: A New Class of Models of the Active Site of the Photosynthetic Water Oxidase. J. Am. Chem. Soc. 1997, 119, 6670.

(62) Limburg, J.; Vrettos, J. S.; Liable-Sands, L. M.; Rheingold, A. L.; Crabtree, R. H.; Brudvig, G. W., A Functional Model for O-O Bond Formation by the O2-Evolving Complex in Photosystem II. Science $1999,283,1524$.

(63) Limburg, J.; Vrettos, J. S.; Chen, H.; de Paula, J. C.; Crabtree, R. H.; Brudvig, G. W., Characterization of the $\mathrm{O}_{2}$-Evolving Reaction Catalyzed by $\left[(\right.$ terpy $)\left(\mathrm{H}_{2} \mathrm{O}\right) \mathrm{Mn}^{\mathrm{III}}(\mathrm{O})_{2} \mathrm{Mn}^{\mathrm{IV}}\left(\mathrm{OH}_{2}\right)($ terpy $\left.)\right]\left(\mathrm{NO}_{3}\right)_{3}$ (terpy $=2,2^{`}: 6,2^{‘}$ '-Terpyridine). J. Am. Chem. Soc. 2001, 123, 423.
(64) Chen, H.; Faller, J. W.; Crabtree, R. H.; Brudvig, G. W., Dimer-ofDimers Model for the Oxygen-Evolving Complex of Photosystem II. Synthesis and Properties of $\left[\mathrm{Mn}^{\mathrm{NV} 4} \mathrm{O}_{5}(\text { terpy })_{4}\left(\mathrm{H}_{2} \mathrm{O}\right)_{2}\right]\left(\mathrm{ClO}_{4}\right)_{6}$. J. Am. Chem. Soc. 2004, 126, 7345.

(65) Chen; Collomb, M.-N.; Duboc, C.; Blondin, G.; Rivière, E.; Faller, J. W.; Crabtree, R. H.; Brudvig, G. W., New Linear High-Valent Tetranuclear Manganese-Oxo Cluster Relevant to the Oxygen-Evolving Complex of Photosystem II with Oxo, Hydroxo, and Aqua Coordinated to a Single Mn(IV). Inorg. Chem. 2005, 44, 9567.

(66) Dubé, C. E.; Wright, D. W.; Pal, S.; Bonitatebus, P. J.; Armstrong, W. H., Tetranuclear Manganese-Oxo Aggregates Relevant to the Photosynthetic Water Oxidation Center. Crystal Structure, Spectroscopic Properties and Reactivity of Adamantane-Shaped $\left[\mathrm{Mn}_{4} \mathrm{O}_{6}(\text { bpea })_{4}\right]^{4+}$ and the Reduced Mixed-Valence Analog $\left[\mathrm{Mn}_{4} \mathrm{O}_{6}(\text { bpea })_{4}\right]^{3+}$. J. Am. Chem. Soc. 1998, 120, 3704.

(67) Chan, M. K.; Armstrong, W. H., Tetranuclear manganese-oxo complex with a 2.7 A Mn-Mn separation and intramolecular $\mathrm{H}_{2} \mathrm{O}-(\mathrm{mu}-$ $\mathrm{O})$ hydrogen-bonded contacts: $\left[\mathrm{Mn}_{4} \mathrm{O}_{2}(\mathrm{TPHPN})_{2}\left(\mathrm{H}_{2} \mathrm{O}\right)_{2}\left(\mathrm{CF}_{3} \mathrm{SO}_{3}\right)_{2}\right]\left(\mathrm{CF}_{3} \mathrm{SO}_{3}\right)_{3}$. Possible mode for binding of water at the active site of the oxygen-evolving complex in photosystem II. J. Am. Chem. Soc. 1990, 112, 4985.

(68) Nguyen, A. I.; Suess, D. L. M.; Darago, L. E.; Oyala, P. H.; Levine, D. S.; Ziegler, M. S.; Britt, R. D.; Tilley, T. D., Manganese-Cobalt Oxido Cubanes Relevant to Manganese-Doped Water Oxidation Catalysts. J. Am. Chem. Soc. 2017, 139, 5579.

(69) Nguyen, A. I.; Darago, L. E.; Balcells, D.; Tilley, T. D., Influence of a "Dangling" $\mathrm{Co}$ (II) Ion Bound to a $\left[\mathrm{MnCo}_{3} \mathrm{O}_{4}\right]$ Oxo Cubane. J. Am. Chem. Soc. 2018, 140, 9030.

(70) Kanady, J. S.; Tsui, E. Y.; Day, M. W.; Agapie, T., A Synthetic Model of the Mn3Ca Subsite of the Oxygen-Evolving Complex in Photosystem II. Science 2011, 333, 733.

(71) Carver, G.; Thut, M.; Noble, C.; Tregenna-Piggott, P. L. W., Theory of High-Spin $\mathrm{d}^{4}$ Complexes: An Angular-Overlap Model Parametrization of the Ligand Field in Vibronic-Coupling Calculations. J. Chem. Theory Comput. 2008, 4, 603.

(72) Tregenna-Piggott, P. L. W.; Weihe, H.; Barra, A.-L., High-Field, Multifrequency EPR Study of the $\left[\mathrm{Mn}\left(\mathrm{OH}_{2}\right)_{6}\right]^{3+}$ Cation: Influence of $\pi$-Bonding on the Ground State Zero-Field-Splitting Parameters. Inorg. Chem. 2003, 42, 8504.

(73) Reed, C. J.; Agapie, T., Tetranuclear Fe Clusters with a Varied Interstitial Ligand: Effects on the Structure, Redox Properties, and Nitric Oxide Activation. Inorg. Chem. 2017, 56, 13360.

(74) Gupta, R.; Taguchi, T.; Lassalle-Kaiser, B.; Bominaar, E. L.; Yano, J.; Hendrich, M. P.; Borovik, A. S., High-Spin Mn-Oxo Complexes and Their Relevance to the Oxygen-Evolving Complex Within Photosystem II. Proc. Nat. Acad. Sci. 2015, 112, 5319.

(75) Tsui, E. Y.; Kanady, J. S.; Agapie, T., Synthetic Cluster Models of Biological and Heterogeneous Manganese Catalysts for $\mathrm{O}_{2}$ Evolution. Inorg. Chem. 2013, 52, 13833.

(76) Christou, G., Manganese carboxylate chemistry and its biological relevance. Acc. Chem. Res. 1989, 22, 328.

(77) Thomson, R. K.; Patrick, B. O.; Schafer, L. L., Synthesis, characterization, and reactivity of the first hafnium alkyl complex stabilized by amidate ligands. Can. J. Chem. 2005, 83, 1037.

(78) Xu, J.-Y.; Astner, J.; Walter, O.; Heinemann, F. W.; Schindler, S.; Merkel, M.; Krebs, B., Iron(III) Complexes with the Ligand $\mathrm{N}^{\prime}, \mathrm{N}^{\prime}$ $\operatorname{Bis}[(2$-pyridyl)methyl $]$ ethylenediamine (uns-penp) and Its Amide Derivative N-Acetyl-N ' ,N ' -bis[(2-pyridyl)methyl] ethylenediamine (acetyl-uns-penp). Eur. J. Inorg. Chem. 2006, 2006, 1601.

(79) Kampert, E.; Janssen, F. F. B. J.; Boukhvalov, D. W.; Russcher, J. C.; Smits, J. M. M.; de Gelder, R.; de Bruin, B.; Christianen, P. C. M.; Zeitler, U.; Katsnelson, M. I.; Maan, J. C.; Rowan, A. E., LigandControlled Magnetic Interactions in $\mathrm{Mn}_{4}$ Clusters. Inorg. Chem. 2009, 48, 11903. 
(80) Kütt, A.; Leito, I.; Kaljurand, I.; Sooväli, L.; Vlasov, V. M.; Yagupolskii, L. M.; Koppel, I. A., A Comprehensive Self-Consistent Spectrophotometric Acidity Scale of Neutral Brønsted Acids in Acetonitrile. J. Org. Chem. 2006, 71, 2829.

(81) Nguyen, A. I.; Wang, J.; Levine, D. S.; Ziegler, M. S.; Tilley, T. D., Synthetic control and empirical prediction of redox potentials for $\mathrm{Co}_{4} \mathrm{O}_{4}$ cubanes over a $1.4 \mathrm{~V}$ range: implications for catalyst design and evaluation of high-valent intermediates in water oxidation. Chem. Sci. 2017, 8, 4274.

(82) Rappaport, F.; Guergova-Kuras, M.; Nixon, P. J.; Diner, B. A.; Lavergne, J., Kinetics and Pathways of Charge Recombination in Photosystem II. Biochemistry2002, 41, 8518.

(83) Chilton, N. F.; Anderson, R. P.; Turner, L. D.; Soncini, A.; Murray, K. S., PHI: A powerful new program for the analysis of anisotropic monomeric and exchange-coupled polynuclear $\mathrm{d}$ - and $\mathrm{f}$ block complexes. J. Comput. Chem. 2013, 34, 1164.

(84) Krzystek, J.; Ozarowski, A.; Telser, J., Multi-frequency, high-field EPR as a powerful tool to accurately determine zero-field splitting in high-spin transition metal coordination complexes. Coord. Chem. Rev. 2006, 250, 2308.

(85) Telser, J.; Ozarowski, A.; Krzystek, J., High-frequency and -field electron paramagnetic resonance of transition metal ion (d block) coordination complexes. In Electron Paramagnetic Resonance: Volume 23, The Royal Society of Chemistry: 2013; Vol. 23, pp 209.

(86) Su, J.-H.; Cox, N.; Ames, W.; Pantazis, D. A.; Rapatskiy, L.; Lohmiller, T.; Kulik, L. V.; Dorlet, P.; Rutherford, A. W.; Neese, F.; Boussac, A.; Lubitz, W.; Messinger, J., The electronic structures of the $\mathrm{S}_{2}$ states of the oxygen-evolving complexes of photosystem II in plants and cyanobacteria in the presence and absence of methanol. Biochim. Biophys. Acta - Bioenergetics 2011, 1807, 829.

(87) Pace, R J.; Smith, P.; Bramley, R.; Stehlik, D., EPR saturation and temperature dependence studies on signals from the oxygen-evolving centre of photosystem II. Biochim. Biophys. Acta - Bioenergetics 1991, $1058,161$.

(88) Randall, D. W.; Sturgeon, B. E.; Ball, J. A.; Lorigan, G. A.; Chan, M. K.; Klein, M. P.; Armstrong, W. H.; Britt, R. D., ${ }^{55}$ Mn ESE-ENDOR of a Mixed Valence Mn(III)Mn(IV) Complex: Comparison with the Mn Cluster of the Photosynthetic Oxygen-Evolving Complex. J. Am. Chem. Soc. 1995, 117, 11780.

(89) Larson, E.; Haddy, A.; Kirk, M. L.; Sands, R. H.; Hatfield, W. E.; Pecoraro, V. L., Asymmetric mixed-valent complex $\{[\mathrm{Mn}(2-\mathrm{OH}-3,5-$ $\mathrm{Cl}_{2}$-SALPN) $]_{2}$ (THF) $\} \mathrm{ClO}_{4}$ shows a temperature-dependent interconversion between $\mathrm{g}=2$ multiline and low-field EPR signals. $J$. Am. Chem. Soc. 1992, 114, 6263.

(90) Hagen, K. S.; Armstrong, W. H.; Hope, H., Isolation of a bis-oxobridged manganese(III)manganese(IV) intermediate by regulated air oxidation. Synthesis, structure, and properties of dioxobis[tris(aminoethyl)amine] dimanganese (5+)

trifluoromethylsulfonate. Inorg. Chem. 1988, $27,967$.

(91) Brewer, K. J.; Calvin, M.; Lumpkin, R. S.; Otvos, J. W.; Spreer, L. O., Synthesis, structure, and characterization of a mixed-valence manganese(III)-manganese(IV) bis(mu-oxo) complex with a macrocyclic tetraaza ligand. Inorg. Chem. 1989, 28, 4446.

(92) Pal, S.; Gohdes, J. W.; Wilisch, W. C. A.; Armstrong, W. H., Synthesis, structure, and properties of a complex that consists of an $\left\{\mathrm{Mn}_{2} \mathrm{O}_{2}\left(\mathrm{O}_{2} \mathrm{CCH}_{3}\right)\right\}^{2+}$ core and a spanning hexadentate ligand. Inorg. Chem. 1992, 31, 713.

(93) Bashkin, J. S.; Schake, A. R.; Vincent, J. B.; Chang, H. R.; Li, Q.; Huffman, J. C.; Christou, G.; Hendrickson, D. N., Mixed valence manganese-(II, III) and -(III, IV) dinuclear complexes: preparation, structure, magnetochemistry, and e.s.r. spectra of $\mathrm{Mn}_{2}$ (biphen) $)_{2}($ biphenH)(bpy) 2 and $\mathrm{Mn}_{2} \mathrm{O}_{2} \mathrm{Cl}_{2}(\mathrm{OAc})(\text { bpy })_{2}\left(\right.$ biphenH $\mathrm{H}_{2}=2,2^{\prime}$-biphenol, bpy $=2,2^{\prime}$ bipyridine). J. Chem. Soc., Chem. Commun. 1988, 700.

(94) Wieghardt, K.; Bossek, U.; Zsolnai, L.; Huttner, G.; Blondin, G.; Girerd, J.-J.; Babonneau, F., A novel mixed-valent Mn-Mn-dimer,
$\left[\mathrm{L}_{2} \mathrm{Mn}_{2}(\mu-\mathrm{O})_{2}\left(\mu-\mathrm{MeCO}_{2}\right)\right]\left[\mathrm{BPh}_{4}\right]_{2} \cdot \mathrm{MeCN}$ : crystal structure, magnetic properties, and e.s.r. spectrum ( $\mathrm{L}=1,4,7$-triazacyclononane $)$.J. Chem. Soc., Chem. Commun. 1987, 651.

(95) Schäfer, K.-O.; Bittl, R.; Zweygart, W.; Lendzian, F.; Haselhorst, G.; Weyhermüller, T.; Wieghardt, K.; Lubitz, W., Electronic Structure of Antiferromagnetically Coupled Dinuclear Manganese $\left(\mathrm{Mn}^{\mathrm{III}} \mathrm{Mn}^{\mathrm{IV}}\right)$ Complexes Studied by Magnetic Resonance Techniques. J. Am. Chem. Soc. 1998, 120, 13104.

(96) Stoll, S.; Schweiger, A., EasySpin, a comprehensive software package for spectral simulation and analysis in EPR. J. Magn. Reson. 2006, 178, 42 .

(97) Cox, N.; Rapatskiy, L.; Su, J.-H.; Pantazis, D. A.; Sugiura, M.; Kulik, L.; Dorlet, P.; Rutherford, A. W.; Neese, F.; Boussac, A.; Lubitz, W.; Messinger, J., Effect of $\mathrm{Ca}^{2+} / \mathrm{Sr}^{2+}$ Substitution on the Electronic Structure of the Oxygen-Evolving Complex of Photosystem II: A Combined Multifrequency EPR, ${ }^{55} \mathrm{Mn}-\mathrm{ENDOR}$, and DFT Study of the $\mathrm{S}_{2}$ State. J. Am. Chem. Soc. 2011, 133, 3635.

(98) Kulik, L. V.; Epel, B.; Lubitz, W.; Messinger, J., Electronic Structure of the $\mathrm{Mn}_{4} \mathrm{O}_{\mathrm{x}} \mathrm{Ca}$ Cluster in the $\mathrm{S}_{0}$ and $\mathrm{S}_{2}$ States of the OxygenEvolving Complex of Photosystem II Based on Pulse ${ }^{55} \mathrm{Mn}$-ENDOR and EPR Spectroscopy. J. Am. Chem. Soc. 2007, 129, 13421.

(99) Schosseler, P.; Wacker, T.; Schweiger, A., Pulsed ELDOR detected NMR. Chem. Phys. Lett. 1994, 224, 319.

(100) Cox, N.; Lubitz, W.; Savitsky, A., W-band ELDOR-detected NMR (EDNMR) spectroscopy as a versatile technique for the characterisation of transition metal-ligand interactions. Mol. Phys. 2013, 111, 2788.

(101) Cox, N.; Nalepa, A.; Lubitz, W.; Savitsky, A., ELDOR-detected NMR: A general and robust method for electron-nuclear hyperfine spectroscopy? J. Magn. Reson. 2017, 280, 63.

(102) Lorigan, G. A.; Britt, R. D., Electron spin-lattice relaxation studies of different forms of the $S_{2}$ state multiline EPR signal of the Photosystem II oxygen-evolving complex. Photosynth. Res. 2000, 66, 189.

TOC Graphic:

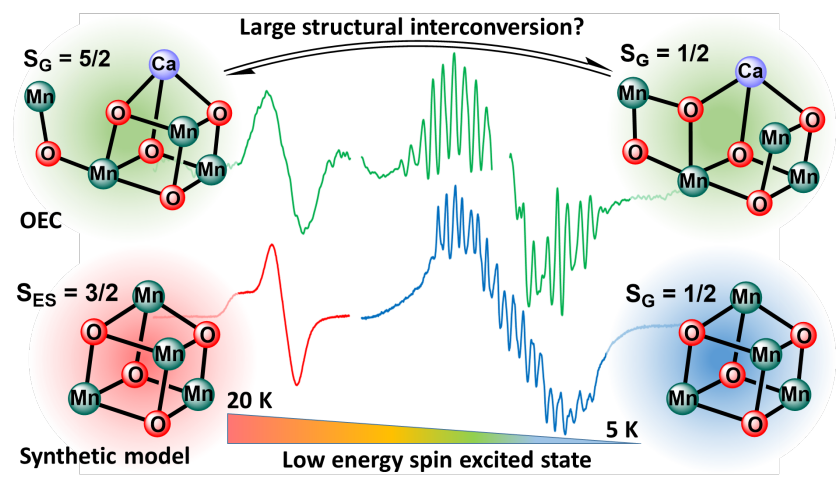

